\title{
CAMINHABILIDADE: Análise no Entorno de Estações do Metrô de Salvador - Ba
}

\author{
Verônica Vaz Oliveira Barbosa \\ Universidade Federal da Bahia - UFBA. \\ vera.vazz@gmail.com
}

\section{RESUMO}

Este trabalho compreende uma dissertação de mestrado apresentada ao Programa de Pós-Graduação em Arquitetura e Urbanismo da Universidade Federal da Bahia (PPGAU/UFBA) e busca avaliar a caminhabilidade no entorno de duas estações da linha 1 do metrô de Salvador. Foram escolhidas as estações Brotas e a Bonocô, por suas características similares (estarem situadas na avenida de vale Mário Leal Ferreira) e diferentes (a implantação no espaço urbano). A metodologia adotada consiste em avaliar trechos de calçadas a partir de oito critérios de caminhabilidade (organizados em uma tabela), englobando três qualidades básicas: atratividade, conforto e segurança para o pedestre ao longo do percurso. Os resultados obtidos permitiram entender como se dá o planejamento urbano da cidade e a forma como o pedestre está inserido dentro de seus deslocamentos. O objetivo do trabalho é auxiliar a gestão urbana municipal para a melhoria das condições de deslocamento a pé na capital baiana.

Palavras chave: caminhabilidade, calçadas, planejamento urbano, estações do metrô.

\section{ABSTRACT}

This work comprises a master's dissertation presented to the Postgraduate Program in Architecture and Urbanism of the Federal University of Bahia (PPGAU / UFBA) and seeks to evaluate the walkability around two stations of line 1 of the Salvador subway. The stations Brotas and Bonocô were chosen because of their similar characteristics (located on the Mário Leal Ferreira valley avenue) and different (the implantation in urban space). The methodology adopted is to evaluate stretches of sidewalks from eight walkability criteria (organized in a table), encompassing three basic qualities: attractiveness, comfort and safety for the pedestrian along the route. The results obtained allowed to understand how the urban planning of the city occurs and the way the pedestrian is inserted within its displacements. The objective of this work is to help municipal urban management to improve walking conditions in the capital of Bahia.

Keywords: walkability, sidewalks, urban planning, subway stations. 


\section{INTRODUÇÃO}

Desde o higienismo no início do século XX ao macroplanejamento da urbanização nos anos 1970, o modelo de cidade visava à abertura de largas avenidas, que faziam a articulação entre bairros, centro e extensão das cidades através dos transportes motorizados (cidade sobre pneus).

O enfoque desta pesquisa está na dimensão humana e na orientação da cidade para o pedestre. A temática dos caminhos acessíveis aos pedestres e aos modais de transporte não motorizados não é vista como uma forma real de deslocamento na capital baiana.

Como afirmam Paixão (2011) e Barros (2014), em sociedades com grande desigualdade social (situação de Salvador), existe preconceito associado aos modais de transporte não motorizados, que são tratados como sinônimos da realidade de pessoas de baixa renda.

Em 2005 surge no Brasil a Política Nacional da Mobilidade Urbana Sustentável - PNMU, adotada pelo Ministério das Cidades, que incentiva a mobilidade urbana sustentável e universal, a partir de ações articuladas entre a União, os Estados, os Municípios, e a população. As diretrizes da política visam uma apropriação democrática da cidade e do espaço público, a partir de deslocamentos seguros, do transporte coletivo eficiente e do maior uso dos meios não motorizados.

Em 2012 surge a Nova Lei de Mobilidade Urbana (LEI № 12.587/12, de 03 de janeiro de 2012), que institui a Política Nacional de Mobilidade Urbana. Através do PlanMob (caderno de referência nacional para a elaboração do Plano de Mobilidade Urbana), traz a oportunidade de repensar as cidades a partir do momento que prioriza os modos de transporte coletivo e não-motorizados, bem como uma maior integração modal.

Segundo a lei, o transporte não motorizado tem prioridade sobre o transporte motorizado e as prefeituras têm o dever e a obrigação de garantir esse fato. O mesmo diz o Código de Trânsito Brasileiro, em que a segurança de pedestres no trânsito, tem prioridade sobre a segurança de todos os condutores e passageiros de veículos, motorizados ou não.

O sucesso do planejamento urbano, já visto em diversas cidades do mundo como: Amsterdã, Barcelona, Berlim, Bogotá e Curitiba, é o conjunto dos meios não motorizados, com os meios coletivos, ou seja, a intermodalidade de transportes. Diferente do pensamento ainda insistente do crescimento da cidade baseado em infraestruturas viárias, que suportem cada vez mais carros.

Assim, a caminhabilidade, em conjunto com a intermodalidade do transporte, é o que conecta a cidade e pedestre, ao direito a espaços abertos e acessíveis. $O$ ato de caminhar é cognitivo, depende de cada indivíduo e se enquadra às diferentes características antropométricas e sensoriais.

Os modais não motorizados, em especial o caminhar, agregam vantagens ao ambiente urbano, pois aumentam a autonomia de quem os utilizam, elevando a qualidade de vida, aumentando a segurança e tornando-os dinâmicos.

Já os modais motorizados coletivos (transportes públicos de massa) são polos atratores de pedestres e mudam a dinâmica da cidade. O metrô, em particular, é uma solução eficiente para o deslocamento nas cidades, pois além de transportar uma alta capacidade de usuários (da ordem de 60 mil passageiros/ hora/ sentido) e de se integrar aos demais modos de transporte, o faz com alta velocidade, regularidade e boas condições de segurança. O metrô conecta a micro e a macroacessibilidade.

Mediante este contexto, o objetivo geral deste artigo é, a partir do entendimento do espaço do pedestre na cidade de Salvador e da sua morfologia urbana atual, pensada para os veículos, e mais precisamente no planejamento urbano atual, comprometido com a conclusão das obras do metrô, apesentar a avaliação dos deslocamentos a pé nas calçadas do entorno de duas estações da Linha 1 do metrô de Salvador ${ }^{1}$, que teve como medida a caminhabilidade.

\footnotetext{
${ }_{1}^{1}$ Para saber mais sobre a caminhabilidade no entorno das duas estações da linha 1 do metrô de Salvador, ver Barbosa (2016).
} 


\section{PEDESTRE E A CAMINHABILIDADE}

Lo (2009) define que a atividade do pedestre é passível de ser comparada com outros meios veiculares, tais como dirigir e andar de bicicleta. Por muito tempo, foi a principal forma para se vencer as distâncias, sendo os pedestres, inicialmente, os protagonistas das ruas. Nesta lógica Francesco Careri (2013:27), que traz a abordagem da ação estética do caminhar, afirma que "foi caminhando que o homem começou a construir a paisagem natural que o circundava".

São vários os motivos que levam a pessoa a caminhar, tanto relacionados ao transporte, quanto ao simples ato de flanar: o deslocamento de um ponto de origem para um destino; o intercâmbio entre modais; caminhar como exercício físico (recreação); lazer (compras), ou mesmo como forma de protesto na cidade. É intrínseco a natureza do homem e é importante desassocia-lo dos estereótipos ligados à marginalidade e à pobreza.

Paixão (2011:22) afirma que a circulação a pé "deve funcionar como uma opção natural para as pessoas se deslocarem nas ruas e este deve ser o ponto de partida para que aconteça a interação das redes de transportes das cidades".

Gehl (2013:32) diz que o pedestre é quem tem "orientação horizontal, frontal, linear, e que anda no máximo a $5 \mathrm{~km} / \mathrm{h}$ ". Desta forma, incentivar, a opção do cidadão pelo caminhar deve ser o objetivo das intervenções urbanas, proporcionando espaços públicos de convívio mais perceptíveis à escala e à velocidade do pedestre. Está na caminhabilidade uma forma de viabilizar estas intervenções.

Embora o conceito de Caminhabilidade (Walkability, Andabilidade) venha sendo desenvolvido desde a década de 1950, as pesquisas sobre a qualidade dos deslocamentos de pedestres começam a ganhar maior atenção nos anos 2000 a partir da conferência WALK 21, em Londres na Inglaterra.

Desde então encontramos na literatura, tanto trabalhos que procuram definir quantitativamente quanto os que buscam definir qualitativamente as características que tornam um ambiente agradável para se caminhar.

O presente trabalho entende o termo Caminhabilidade como a capacidade do espaço público em permitir o ato de caminhar. Já o Índice de Caminhabilidade Urbana é o grau de adequação desse espaço aos deslocamentos a pé, ou seja, o quanto as calçadas das cidades proporcionam aos pedestres um caminhar seguro, contínuo e confortável.

A realização de avaliações de caminhabilidade ajuda a identificar aspectos de importante influência na utilização das calçadas, sendo possível diagnosticar os problemas para melhorias pontuais imediatas, ou como diz o arquiteto brasileiro Jaime Lerner (2005), para "acupunturas urbanas"2.

\section{BREVES CONSIDERAÇÕES SOBRE A HISTÓRIA, A CONFIGURAÇÃO URBANA E O METRÔ DE SALVADOR}

Edificada em acrópole, sobre uma falha tectônica com altitude entre 60 e 80 metros, em frente à baía de Todos os Santos, a cidade de Salvador, em 1549, foi implantada por Tomé de Souza, como capital do Brasil.

A planta da cidade veio de Portugal e a escolha por esse sítio urbano tinha lógica defensiva. Seu núcleo histórico possuía um arruamento de quadrículas adaptadas ao relevo. A característica de defesa da cidade influenciou seu desenvolvimento nos séculos seguintes (XVII e XVIII).

O tecido urbano foi expandindo inicialmente seguindo as linhas de cumeadas (parte alta), com o cultivo e o fornecimento de subsistência nos vales (parte baixa). No início do século XIX Salvador ocupava o dobro do seu espaço original.

\footnotetext{
${ }^{2}$ Embora o conceito de Acupuntura Urbana tenha sido criado pelo arquiteto e teórico social finlandês Marco Casagrande, Jaime Lerner $(2005$, p.8) entende o termo como "uma centelha que inicia uma ação e a subsequente propagação desta ação", e que faz parte do processo do planejamento urbano.
} 
Delgado (2014:202) afirma, em referência ao transporte urbano neste século, que "os sistemas de bondes, ascensores e planos inclinados compartilhavam os espaços públicos com pedestres em um sistema integrado capaz de vencer os obstáculos topográficos existentes na cidade de uma forma muito original".

Os equipamentos ascensores usados para facilitar o deslocamento dos pedestres na topografia peculiar da cidade, se resumem a cinco: os planos inclinados Gonçalves (Séc. XIX), Pilar (Séc. XIX) e LiberdadeCalçada (Séc. XX), o Elevador Lacerda (Séc. XIX) e o Elevador do Taboão (Séc. XIX). Embora a cidade tenha tido essas experiências de integração modal, não houve avanços significativos nos anos seguintes.

Na década de 1940, o Escritório do Plano Urbanístico da Cidade do Salvador - EPUCS traz a experiência de elaboração de um plano global para Salvador, coordenado pelo engenheiro sanitarista Mário Leal Ferreira.

Nos anos de 1950, com uma explosão demográfica, a cidade retoma o crescimento. Os vales com suas avenidas asfaltadas são ocupados pela população mais pobre, assim como as encostas. No fim da década de 1960, surgem as avenidas de vale, trazendo maior fluidez para a circulação dos automóveis. Elas possibilitam o acesso rápido a lugares distantes do centro tradicional.

A expansão da cidade em conjunto com a topografia acidentada (figura 1), confere a Salvador um tecido urbano pouco convencional e segregado sócio-espacialmente. Estes fatores são limitantes para as condições da mobilidade da cidade, principalmente por não se pensar nos deslocamentos verticais.

Ao longo das décadas de 1970 e 1980 acontecem alguns planos urbanísticos na cidade. Havia até então uma sequência de tentativas de construção de um transporte de massa. Todos os planos enxergavam essa necessidade, e recomendavam (cada um à sua maneira) um traçado que ligasse o Centro Histórico, com novas áreas em expansão.

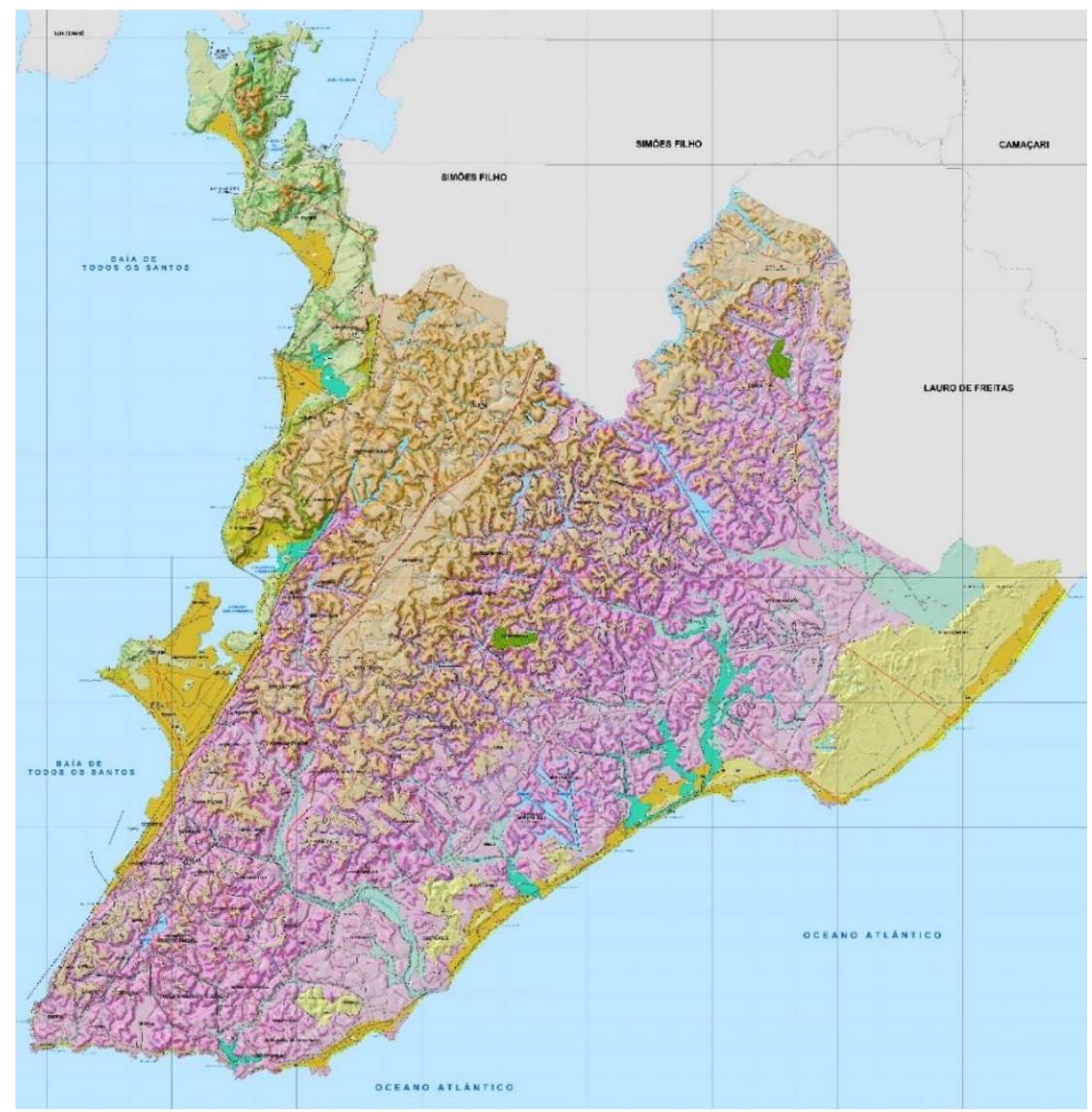

Figura 1: Carta Geológica de Salvador

Elaborado pela autora a partir de dados da Prefeitura de Salvador 
A escala menor do planejamento urbano de Salvador, acontece no início da década de 1980, com as intervenções feitas na cidade pelo arquiteto carioca João Filgueiras Lima, o Lelé, para a RENURB (Companhia de Renovação urbana de Salvador).

Diante de sua compreensão da complexidade da geografia da cidade, Lelé desenvolve o projeto de passarelas padronizadas, fazendo a conexão entre cumeadas e vales. As "passarelas de Lelé" ao longo dos anos foram construídas em diversas áreas da cidade, de forma indiscriminada (e algumas vezes inadequada), não apenas nas avenidas de vale como mostra a figura 2. Elas viraram marca da paisagem urbana de Salvador.

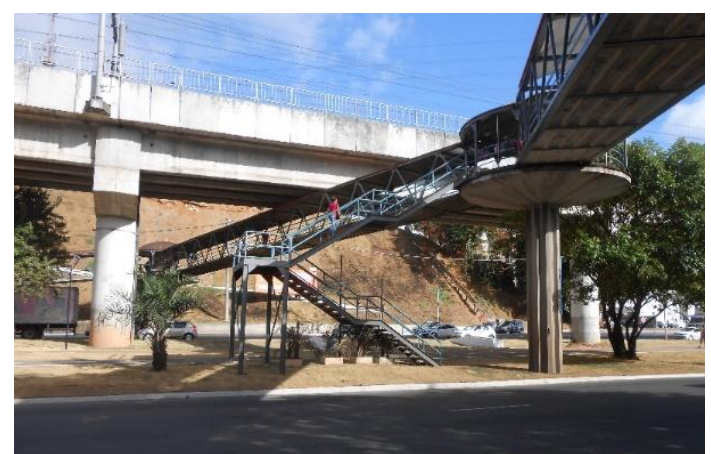

Figura 2: Vista da "Passarela de Lelé" (articulada com uma escada) localizada na Avenida Bonocô.

(Barbosa, 2015)

A atualização da Pesquisa Domiciliar Origem-Destino feita em 1998, verificou a viabilidade do projeto do Sistema Metroviário de Salvador e Lauro de Freitas (SMSL), indicando um traçado com base nas rotas expressivas do transporte coletivo de ônibus. Desta forma, o metrô não conecta as cumeadas, ele segue pelos eixos das avenidas de vale predominantes da cidade.

A construção da Linha 1 do metrô inicia, com atraso nos anos 2000. Era previsto a conclusão de oito estações (Lapa à Pirajá) com 11,9 km até 2003. Posteriormente, seriam executados os 2,9 km até Pau da Lima. Mas houve diversas paralizações.

Em 2008 é lançado o projeto da Linha 2 e em 2014, após quatorze anos desde o lançamento do projeto, o metrô começa a funcionar no trecho da Linha 1, de forma gratuita e com velocidade de teste para a adaptação da população. A operação comercial do sistema metroviário de Salvador teve início em 2016.

A figura 3 mostra o mapa das linhas 1 e 2 do metrô de Salvador. Hoje, apenas oito estações da Linha 1 estão em funcionamento: Lapa; Campo da Pólvora; Brotas; Bonocô; Acesso Norte, Retiro; Bom Juá e Pirajá. A construção da Linha 2 está em andamento.

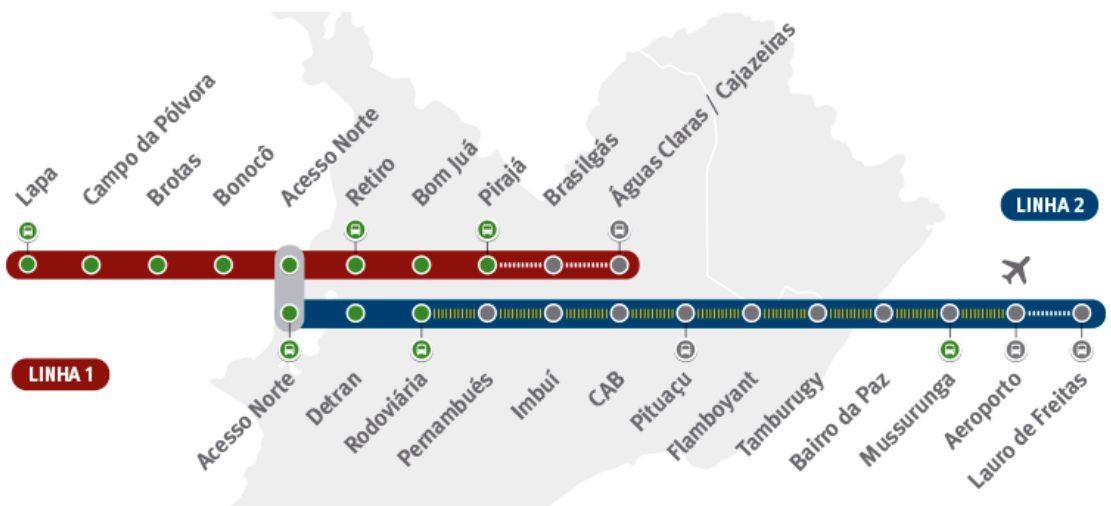

LEGENDA:
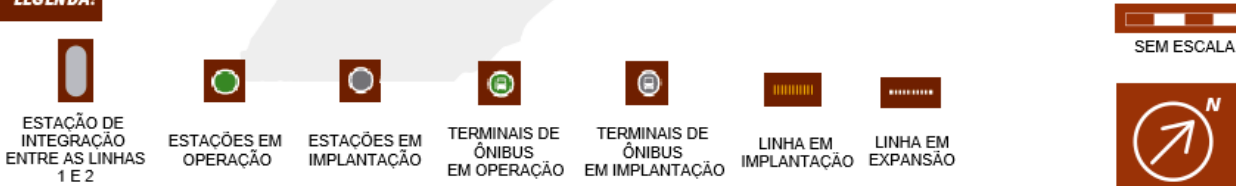

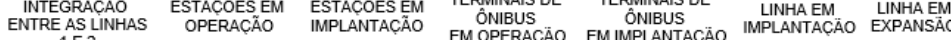

Figura 3: Mapa das Linhas 1 e 2 do Metrô de Salvador

Elaborado pela autora a partir de dados da CCR Metrô Bahia 
Atualmente Salvador mantém sua característica de cidade complexa, polinucleada e conurbada. Ainda que os deslocamentos realizados pelo modo a pé na cidade sejam significativos $\left(35,3 \%\right.$ do total $\left.{ }^{3}\right)$, o modelo de transporte público é precário e exclusivamente baseado no ônibus. A microacessibilidade, com os deslocamentos de curta distância e a integração modal não são pensados.

As implantações das estações do metrô, em sua maioria seguindo o eixo viário das avenidas de vale, evidenciam a fratura espacial existente devido ao relevo da cidade. Por conta disto cria-se um problema de acesso às mesmas, feitos por meio de conjuntos de rampas e passarelas, com inclinações superiores aos $8,33 \%$ máximos recomendados pela norma brasileira.

Não há dentro da agenda de planejamento urbano de Salvador, um programa que pense a cidade como uma rede integrada, levando em consideração principalmente sua topografia difícil e os desgastes físicos necessários para fazer estes deslocamentos verticais. Exemplo disto são as escadarias espalhadas pela cidade, boa parte delas foram feitas para vencer entre vinte e quarenta metros.

\section{METODOLOGIA DE AVALIAÇÃO DE CAMINHABILIDADE}

A metodologia utilizada neste trabalho é a Tabela de Avaliação dos Índices de Caminhabilidade (figura 4) elaborada por Rodrigues e Matos (2012) que se insere nas atividades do Núcleo de Estudos em Mobilidade Urbana - NMob, grupo de pesquisa ligado à Faculdade de Arquitetura da Universidade Federal da Bahia e ao Núcleo de Arquitetura e Urbanismo da Universidade Federal de Sergipe (UFS).

A escolha desta tabela decorre do seu formato compacto e de fácil entendimento, que sua utilização não apenas por um corpo técnico especializado, mas também por leigos. Da mesma forma, por seu formato simplificado, a tabela pode ser usada para avaliar qualquer calçada da cidade, e, consequentemente, o entorno de qualquer uma das estações do metrô.

Para o item atratividade são definidos os critérios: (1) Densidade de Pessoas e (2) Uso do Solo Lindeiro. Para conforto são: (1) Densidade de Pessoas; (3) Largura da calçada; (4) Condições do piso/ existência de obstáculos/ nivelamento; (5) Proteção contra intempéries e (6) Mobiliário urbano. Por fim, os critérios para avaliar a segurança são: (7) Segurança de travessia para o pedestre e (8) Proteção do tráfego local (velocidade e proximidade dos automóveis).

\footnotetext{
${ }^{3}$ Segundo dados de uma pesquisa de mobilidade realizada em 2012 pela Secretaria de Infraestrutura do Estado, na Região Metropolitana de Salvador, o deslocamento por modais não motorizados na cidade são $36,2 \%$ do total, na qual $35,3 \%$ são deslocamento feitos a pé e $0,9 \%$ deslocamentos feitos de bicicleta. Para mais informações acessar: http://www.mobilize.org.br (Consulta: 15/10/2015)
} 


\section{ÍNDICES DE CAMINHABILIDADE}

\begin{tabular}{|c|c|c|c|c|c|}
\hline \multicolumn{6}{|l|}{ Quadra/ trecho: } \\
\hline \multicolumn{6}{|l|}{ Sentido: } \\
\hline \multicolumn{6}{|c|}{ Data:__ Dia da semana:_ } \\
\hline \multicolumn{3}{|r|}{ CRITÉRIOS } & $\begin{array}{c}\text { NOTA } \\
(0-5)\end{array}$ & $\begin{array}{c}\text { NOTA } \\
(0-5)\end{array}$ & MÉDIA \\
\hline \multirow{2}{*}{ ATRATIVIDADE } & 1 & Densidade de Pessoas & & & \\
\hline & 2 & Uso do Solo Lindeiro & & & \\
\hline \multirow{6}{*}{ CONFORTO } & & \multicolumn{4}{|c|}{ Fluência do tráfego sobre a calçada } \\
\hline & \multirow{2}{*}{3} & Densidade De Pessoas & & & \\
\hline & & Largura da Calçada & & & \\
\hline & 4 & $\begin{array}{l}\text { Condições do piso*/ Existência } \\
\text { de Obstáculos/ Nivelamento do piso }\end{array}$ & & & \\
\hline & 5 & Proteção intempéries & & & \\
\hline & 6 & Mobiliário urbano** & & & \\
\hline \multirow[b]{2}{*}{ SEGURANÇA } & 7 & Segurança de travessoa para o pedestre & & & \\
\hline & 8 & $\begin{array}{l}\text { Proteção do tráfego local (velocidade e } \\
\text { proximidade/ separação física) }\end{array}$ & & & \\
\hline RESULTADOS & & Média individual e geral & & & \\
\hline
\end{tabular}

* Condições do piso: Tipo de pavimentação:

** Mobiliário Urbano: Lixeiras:___ Bancos: ___ Telefones Públicos:___ Para ciclos:

\begin{tabular}{|c|c|c|c|c|c|c|}
\hline \multicolumn{3}{|c|}{ LD } & \multicolumn{3}{|c|}{ LE } & \multirow[t]{2}{*}{ OBSERVAÇŌES: } \\
\hline & QNT. PESSOAS & NOTA & & QNT. PESSOAS & NOTA & \\
\hline 1 & & & 1 & & & 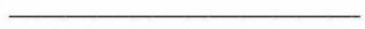 \\
\hline 2 & & & 2 & & & \\
\hline 3 & & & 3 & & & \\
\hline 4 & & & 4 & & & \\
\hline 5 & & & 5 & & & \\
\hline \multicolumn{3}{|c|}{ MÉDIA PARCIAL } & \multicolumn{3}{|c|}{ MÉDIA PARCIAL } & \\
\hline \multicolumn{6}{|c|}{ MÉDIA FINAL } & \\
\hline
\end{tabular}

Figura 4: Tabela de Avaliação dos İndices de Caminhabilidade

Elaborado pela autora com base nos dados de Rodrigues e Matos (2012)

Cada um dos critérios de avaliação possui parâmetros de pontuação, no qual são atribuídas notas de 0 a 5 , que após aplicação nos percursos delimitados sobre a calçada, resultam em uma média final. Desta forma, as notas entre 0 e 2 caracterizam que o deslocamento ao longo da rota é ruim, as notas entre 2 e 3 o deslocamento é regular e, entre 3 e 5 o deslocamento é bom. As notas possuem o mesmo peso.

Para calcular a densidade de pessoas, primeiro critério da tabela, os pesquisadores do NMob utilizaram o método, em que primeiro se divide a extensão do trajeto em cinco distâncias similares, indicando os pontos onde será aferida a densidade. O ideal é um percurso com distância superior a três metros.

Em cada um dos cinco pontos divididos é aferida a densidade e medida a largura da calçada. Para o cálculo da densidade utiliza-se a fórmula onde a densidade é obtida pela divisão do número de pessoas contabilizadas pelo tempo de 2 minutos.

Com os valores de densidade de cada trecho definidos, determina-se notas de 1 a 5 , a partir dos parâmetros de pontuação da densidade de pessoas apresentados na figura 5. Por fim, somam-se as notas e divide-se o valor por cinco, encontrando a densidade média do trajeto.

\begin{tabular}{|l|l|}
\hline Densidade de 01 - 10 & Nota 1 \\
\hline Densidade de 10 - 20 & Nota 2 \\
\hline Densidade de 20 - 30 & Nota 3 \\
\hline Densidade de 30 - 40 & Nota 4 \\
\hline Densidade de 40 - 50 & Nota 5 \\
\hline
\end{tabular}

Figura 5: Tabela dos Parâmetros de Pontuação da densidade de pessoas Elaborado pela autora com base nos dados de Rodrigues e Matos (2012) 
O segundo critério diz respeito ao uso do solo lindeiro. Compreende-se que o uso do solo ao longo da via e a interface destes imóveis (ou lotes) com o espaço público influencia no ato de caminhar. Um percurso com pontuação baixa é pouco atrativo e possível de ser evitado. A figura 6 mostra os parâmetros de pontuação deste critério.

\section{USO DO SOLO LINDEIRO}

\begin{tabular}{|c|c|c|}
\hline NOTA & & DEFINIÇÃO DA PONTUAÇÃO \\
\hline $0-1$ & $\begin{array}{l}\text { Uso do solo lindeiro incompatível com a caminhada, o pedestre } \\
\text { procura evitar o percurso: } \\
\text { esgotos a céu aberto, galpões industriais, oficinas, depósitos de } \\
\text { lixo, edificações fechadas... }\end{array}$ & $\begin{array}{l}0 \text { - ocorrência em grande parte } \\
\text { do trecho. } \\
1 \text { - ocorrência em até metade } \\
\text { do trecho, aproximadamente. }\end{array}$ \\
\hline $2-3$ & $\begin{array}{l}\text { Uso do solo lindeiro incompativel de pouco interesse, não pre- } \\
\text { judica, mas não incentiva a caminhada. } \\
\text { Pouca interface entre calçada e edificações. }\end{array}$ & $\begin{array}{l}\text { 2- ocorrência em grande parte } \\
\text { do trecho. } \\
3 \text { - ocorrência em até metade } \\
\text { do trecho, aproximadamente. }\end{array}$ \\
\hline $4-5$ & $\begin{array}{l}\text { Uso do solo lindeiro de grande interesse, incentivando a cami- } \\
\text { nhada. Interface entre calçada e edificações torna a caminhada } \\
\text { agradável. }\end{array}$ & $\begin{array}{l}\text { 4- ocorrência em grande parte } \\
\text { do trecho. } \\
5 \text { - ocorrência em até metade } \\
\text { do trecho, aproximadamente. }\end{array}$ \\
\hline
\end{tabular}

\section{Figura 6: Parâmetros de Pontuação de Uso do Solo Lindeiro}

Elaborado pela autora com base nos dados de Rodrigues e Matos (2012)

O terceiro critério, largura da calçada, influencia na possibilidade de apropriação do espaço urbano pelo pedestre (e na vitalidade da rua). Os parâmetros de pontuação para a largura da calçada (figura 7) são balizados pela NBR 9050 (2015:74), que define como largura mínima 1,20m e recomenda-se reservar $0,70 \mathrm{~m}$ para a faixa de serviço e o restante para a faixa livre (ou passeio).

\section{LARGURA DA CALÇADA}

\begin{tabular}{|c|c|c|}
\hline NOTA & & DEFINIÇÃO DA PONTUAÇÃO \\
\hline $0-1$ & Calçada com menos de $1,50 \mathrm{~m}$ de largura. & $\begin{array}{l}0 \text { - menos de 1,20m (mínimo possivel). Verificar legis- } \\
\text { lação de Salvador. } \\
1 \text { - entre } 1,20 \text { m e 1,50 (mínimo recomendável). }\end{array}$ \\
\hline $2-3$ & Calçada entre $1,50 \mathrm{~m}$ e $2,50 \mathrm{~m}$ de largura. & $\begin{array}{l}2 \text { - entre } 1,50 \mathrm{~m} \text { e } 2,00 \mathrm{~m} . \\
3 \text { - entre } 2,00 \mathrm{~m} \text { e } 2,50 \mathrm{~m}\end{array}$ \\
\hline $4-5$ & Calçada com mais de $2,50 \mathrm{~m}$ de largura. & $\begin{array}{l}4 \text { - entre } 2,50 \mathrm{~m} \text { e } 3,00 \mathrm{~m} \text {. } \\
5 \text { - com mais de } 3,00 \mathrm{~m} \text {. }\end{array}$ \\
\hline
\end{tabular}

Figura 7: Parâmetros de Pontuação da Largura da Calçada

Elaborado pela autora com base nos dados de Rodrigues e Matos (2012)

Os parâmetros referentes ao quarto critério visam avaliar as condições físicas do piso da calçada (figura 8). Se há nivelamento, inclinação fora de norma, obstáculos (de todos os tipos, inclusive de mobiliário urbano), condições da pavimentação, etc. Este item influência na possibilidade de caminhada.

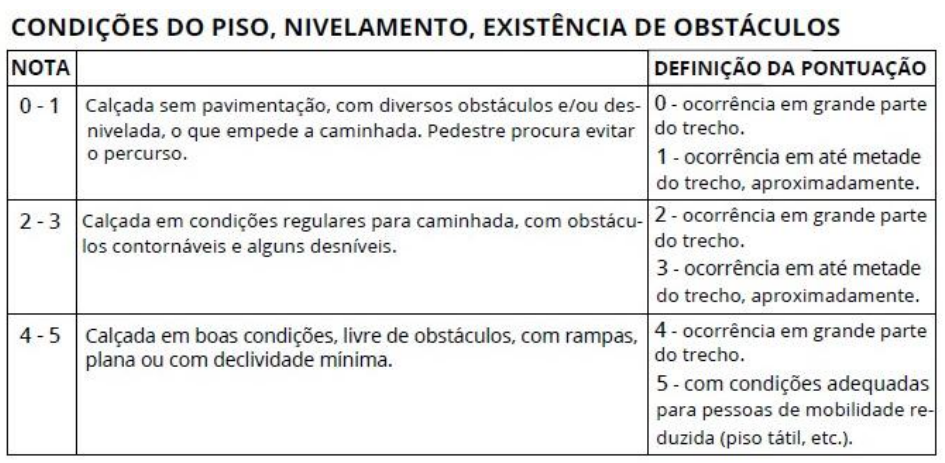

Figura 8: Parâmetros de Pontuação das Condições do Piso da Calçada

Elaborado pela autora com base nos dados de Rodrigues e Matos (2012)

O critério cinco, Proteção de Intempéries (figura 9), afere as possibilidades da calçada em oferecer abrigo (proteção contra o sol e contra a chuva) ao pedestre. É também considerada a implantação e configuração da edificação lindeira na extensão do percurso, devido a produção de sombra. 


\section{PROTEÇÃO DE INTEMPÉRIES}

\begin{tabular}{|c|l|l|}
\hline NOTA & \multicolumn{1}{|c|}{ DEFINIÇÃo DA PONTUAÇÃo } \\
\hline 0 -1 & $\begin{array}{l}\text { Proteção inexistente ou insuficiente contra chuva e } \\
\text { sol: sem sombra, sem arborização. }\end{array}$ & $\begin{array}{l}\text { 0- ocorrência em grande parte do trecho. } \\
1 \text { - ocorrência em até metade do trecho, } \\
\text { aproximadamente }\end{array}$ \\
\hline 2 -3 & $\begin{array}{l}\text { Calçada pontualmente protegida; existência de al- } \\
\text { gumas marquises e árvores. }\end{array}$ & $\begin{array}{l}\text { 2-pontualmente protegida. } \\
\text { 3-pontualmente protegida; com sombra } \\
\text { das edificações pela manhã ou tarde. }\end{array}$ \\
\hline 4 - 5 & $\begin{array}{l}\text { Calçada com proteção total, suficientemente arbo- } \\
\text { rizada ou com marquises. }\end{array}$ & $\begin{array}{l}\text { 4- proteção contra chuva; sombra das edi- } \\
\text { ficações manhã ou tarde. } \\
\text { - sombra e proteção contra chuvas em } \\
\text { boa parte do trecho. }\end{array}$ \\
\hline
\end{tabular}

Figura 9: Parâmetros de Pontuação de Proteção de Intempéries

Elaborado pela autora com base nos dados de Rodrigues e Matos (2012)

O critério seis trata do mobiliário urbano (figura 10), os itens quantificados são equipamentos de uso dos cidadãos, bem como os de suporte às redes de serviço e infraestrutura instalados no espaço público. Não apenas a existência do mobiliário é verificada, mas suas condições de uso.

\section{MOBILIÁRIO URBANO}

\begin{tabular}{|c|c|c|}
\hline NOTA & & DEFINIÇÃO DA PONTUAÇÃO \\
\hline $0-1$ & $\begin{array}{l}\text { Inexistência de mobiliário urbano de apoio (lixeiras, } \\
\text { bancos, telefones públicos,...) ou existência em con- } \\
\text { dições precárias. }\end{array}$ & $\begin{array}{l}0 \text { - ocorrência em grande parte do trecho. } \\
1 \text { - ocorrência em até metade do trecho, } \\
\text { aproximadamente; no restante o mobiliá- } \\
\text { rio é precário, sem manutenção. }\end{array}$ \\
\hline $2-3$ & $\begin{array}{l}\text { Com alguns itens de mobiliário urbano, em boas } \\
\text { condições. }\end{array}$ & $\begin{array}{l}2 \text { - ocorrência em até metade do trecho, } \\
\text { aproximadamente. } \\
3 \text { - ocorrência em grande parte do trecho }\end{array}$ \\
\hline $4-5$ & Calçada bem dotada de mobiliário urbano. & $\begin{array}{l}4 \text { - ocorrência em até metade do trecho, } \\
\text { aproximadamente. } \\
5 \text { - ocorrência em grande parte do trecho }\end{array}$ \\
\hline
\end{tabular}

Figura 10: Parâmetros de Pontuação do Mobiliário Urbano

Elaborado pela autora com base nos dados de Rodrigues e Matos (2012)

No critério sete, Segurança de travessia para o pedestre (figura 11), é onde observamos as questões referentes à sinalização de trânsito: placas indicativas de travessia, de velocidade dos veículos e de alerta; faixas de pedestre e semáforos.

\section{AVALIAÇÃO DE TRAVESSIAS}

\begin{tabular}{|c|l|l|}
\hline NOTA & & \multicolumn{1}{|c|}{ DEFINIÇÃo DA PONTUAÇÃo } \\
\hline 0 -1 & $\begin{array}{l}\text { Travessia totalmente insegura para o pedestre, } \\
\text { sem sinalização: tráfego de veículos flui ininter- } \\
\text { ruptamente. }\end{array}$ & $\begin{array}{l}0 \text { - não há sinalização, tráfego de veículos flui } \\
\text { ininterruptamente em sentidos contrários. } \\
1 \text { - não há sinalização ou há sinalização ape- } \\
\text { nas horizontal, tráfego de veículos flui ininter- } \\
\text { ruptamente em um único sentido. }\end{array}$ \\
\hline 2 - 3 & $\begin{array}{l}\text { Travessia parcialmente segura; apenas semáfo- } \\
\text { ro e veículos. }\end{array}$ & $\begin{array}{l}\text { 2- Travessia em duas etapas, semáforo de ve- } \\
\text { ículos em apenas um dos sentidos; fluxo con- } \\
\text { trário (incl. conversão da outra via) sem inter- } \\
\text { supção, sem faixa de segurança. } \\
3 \text { - Travessia em duas etapas, semáforo de ve- } \\
\text { ículos para os dois fluxos; sem faixa de segu- } \\
\text { rança nem semáforo de pedestre. }\end{array}$ \\
\hline 4 - 5 & $\begin{array}{l}\text { Travessia segura; com semáforo e faixa de pe- } \\
\text { destre. }\end{array}$ & $\begin{array}{l}\text { 4- Fluxo em apenas um sentido, com semáfo- } \\
\text { ro de veículos e sinalização horizontal (faixa de } \\
\text { pedestre). } \\
5 \text { - Segurança total, com semáforo de pedes- } \\
\text { tre e sinalização horizontal (faixa de pedestre) }\end{array}$ \\
\hline
\end{tabular}

Figura 11: Parâmetros de Pontuação da Segurança de travessia para os pedestres Elaborado pela autora com base nos dados de Rodrigues e Matos (2012)

O oitavo e último critério, Proteção do Tráfego Local (figura 12), aborda a sensação de risco do pedestre proporcionada pelos veículos em seu deslocamento. É analisado a proximidade dos automóveis em relação ao pedestre; a velocidade e a existência ou não de barreiras físicas contra o tráfego (balizadores, estacionamento rotativo ao logo do meio fio, etc.). 


\section{PROTEÇÃO DO TRÁFEGO LOCAL (VELOCIDADE E PROXIMIDADE/SEPARAÇÃO FÍSICA)}

\begin{tabular}{|c|l|l|}
\hline NOTA & \multicolumn{1}{|c|}{ DEFINIÇÃo DA PONTUAÇÃo } \\
\hline 0 -1 & $\begin{array}{l}\text { Calçada sem proteção do tráfego local; velocidade } \\
\text { relativamente alta de veículos e/ou tráfego intenso } \\
\text { sem separação física (estacionamento ao longo do } \\
\text { meio fio, por ex.) dos pedestres na calçada. }\end{array}$ & $\begin{array}{l}\text { 0 - sem proteção em grande parte do trecho: } \\
\text { vias largas (avenidas) com tráfego intenso/ve- } \\
\text { locidade alta. } \\
1 \text { - vias estreitas, com tráfego intenso/veloci- } \\
\text { dade alta, sem proteção. }\end{array}$ \\
\hline 2 -3 & Calçada relativamente protegida do tráfego local. & $\begin{array}{l}\text { - tráfego com baixa velocidade, mas sem se- } \\
\text { paração física dos pedestres; largura mín. } 2 \mathrm{~m} . \\
\text { 3- tráfego intenso/velocidade relativamente } \\
\text { alta, mas com proteção física. }\end{array}$ \\
\hline 4 -5 & Calçada totalmente protegida do tráfego local. & $\begin{array}{l}\text { 4- tráfego pouco intenso, com estacionamen- } \\
\text { to ao longo do meio-fio. } \\
\text { 5- rua exclusivamente de pedestres. }\end{array}$ \\
\hline
\end{tabular}

Figura 12: Parâmetros de Pontuação da Proteção do tráfego local

Elaborado pela autora com base nos dados de Rodrigues e Matos (2012)

A adaptação feita pela autora, na tabela de avaliação foi apenas referente à sua apresentação gráfica. A partir de uma melhor organização e disposição dos quadros e informações existentes, foi possível reduzir o número de páginas (de seis passou a quatro), facilitando seu manuseio nas avaliações em campo.

A escolha pelas estações Brotas e Bonocô se dá por dois motivos: as duas estarem localizadas na avenida de vale Mario Leal Ferreira; e por terem a implantação diferente, enquanto a estação Brotas se acomoda na encosta e possui uma ligação direta entre vale e cumeada, a estação Bonocô segue elevada no eixo central da avenida, sem qualquer ligação direta com a topografia que a cerca.

O desenvolvimento de rotas a partir da ligação imediata entre os dois modais de transporte público de passageiros da cidade, ônibus e metrô, teve o intuito de verificar se há de fato, uma preocupação com a integração destes modais e na qualidade do percurso entre eles. Os pontos de ônibus de todas as rotas estão ativos e possuem fluxo.

\section{AVALIAÇÃO DA CAMINHABILIDADE}

\subsection{Estação Brotas}

Com uma área de $2.703,83 \mathrm{~m}^{2}$, a estação está localizada na Travessa Amaral Muniz, s/non, no bairro do Matatu de Brotas, atendendo diretamente este bairro. Ela possui duas plataformas de embarque, acessadas por escadas, escadas rolantes e elevadores. $O$ ingresso à estação é feito por duas entradas: uma pela Avenida Mário Leal Ferreira (Av. Bonocô) e a outra pela Rua das Pitangueiras.

A partir da localização dos pontos de ônibus mais próximos (excluindo os que ficam na própria estação no acesso superior e no inferior), foram definidas quatro rotas (figura 13), todas, tendo como ponto final, a Estação Brotas. 


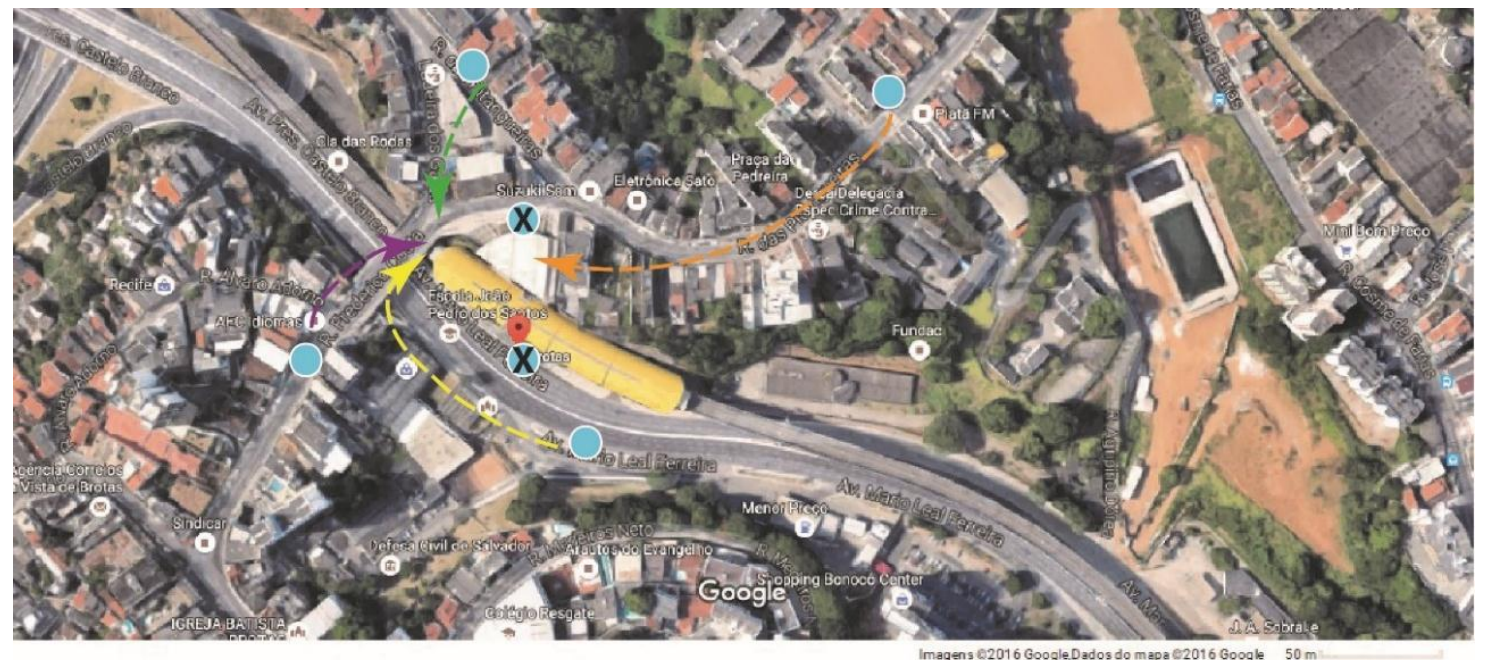

LEGENDA:

X PONTO dE ÓNIBUS NÃO CONSIDERADO PONTO DE ÔNIBUS SENTIDO DAS ROTAS

Figura 13: Identificação das Rotas do entorno da Estação Brotas

Elaborado pela autora com base em imagem do Google Maps.

O bairro na qual a estação Brotas está inserida é habitado tanto por segmentos da classe média e média alta, quanto por segmentos da classe baixa, que em sua conformação ocuparam respectivamente a parte alta e a parte baixa (Vale do Matatu). A região possui um variado tecido urbano.

No percurso da parte baixa, fragmentado pela extensão e velocidade da Av. Bonocô (uma via com velocidade do tráfego de $70 \mathrm{~km} / \mathrm{h}$ ), as edificações estão localizadas de forma dispersa, pontual, com grandes áreas de terreno não edificadas e cercadas por gradis.

$\mathrm{Na}$ da parte alta, a disposição das edificações em relação ao lote é mais densa. Há variedade de tipologias, sendo frequentes casas de um e dois pavimentos, geminadas e edifícios com até quatro pavimentos. As poucas construções mais novas tendem à verticalização e ultrapassam o gabarito local.

A região é carente de áreas de lazer, não há praças, e, quanto à ambiência das ruas, são poucos os trechos arborizados. A predominância é do uso misto, onde há o comércio/serviço no térreo das edificações e a residência nos pavimentos acima.

Do início da Rota 1 (seta amarela na figura 13), na Av. Bonocô, para chegar à Estação Brotas, são percorridos aproximadamente $275 \mathrm{~m}$, sendo necessário fazer um deslocamento vertical por uma escadaria com mais de cinquenta degraus, para acessar a Rua Frederico Costa (figura 14).

A escadaria possui pontos danificados, sem manutenção e não está de acordo com a NBR 9050 (2015), por não possuir corrimãos, ter espelhos com alturas irregulares, não possuir sinalização e boa iluminação. É frequente acontecerem assaltos nela.
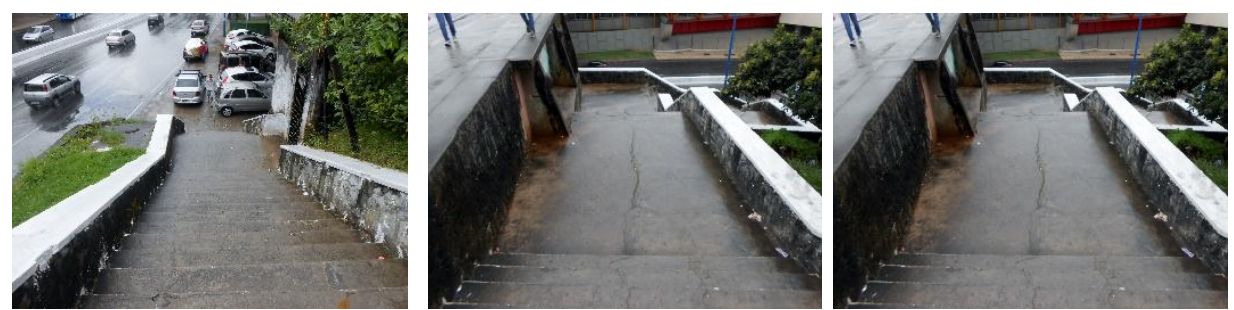

Figura 14: Vistas da escadaria de acesso à Rua Frederico Costa (Barbosa, 2015)

Como mostra a figura 15, a Rota 1 deixa a desejar no mobiliário urbano e na segurança de travessia. Com um índice de caminhabilidade ruim, sua média de caminhabilidade $(1,91)$ foi favorecida pelo critério da densidade de pessoas $(3,6)$, que foi alto devido ao ponto de ônibus com a constante chegada e saída de passageiros. 


\begin{tabular}{|c|c|c|c|c|c|}
\hline \multicolumn{3}{|r|}{ CRITÉRIOS } & $\begin{array}{c}\text { NOTA } \\
\text { (0-5) } \\
\text { LD }\end{array}$ & $\begin{array}{c}\text { NOTA } \\
(0-5) \\
\text { LE }\end{array}$ & MÉDIA \\
\hline \multirow{2}{*}{ ATRATIVIDADE } & 1 & Densidade de Pessoas & 3,6 & & 3,6 \\
\hline & 2 & Uso do Solo Lindeiro & 2,0 & & 2,0 \\
\hline \multirow{6}{*}{ CONFORTO } & \multicolumn{5}{|c|}{ Fluência do tráfego sobre a calçada } \\
\hline & \multirow{2}{*}{3} & Densidade De Pessoas & 3,6 & & 3,6 \\
\hline & & Largura da Calçada & 2,0 & & 2,0 \\
\hline & 4 & $\begin{array}{l}\text { Condições do piso*/ Existência } \\
\text { de Obstáculos/ Nivelamento do piso }\end{array}$ & 2,0 & & 2,0 \\
\hline & 5 & Proteção intempéries & 2,0 & & 2,0 \\
\hline & 6 & Mobiliário urbano** & 1,0 & & 1,0 \\
\hline \multirow[b]{2}{*}{ SEGURANÇA } & 7 & Segurança de travessoa para o pedestre & 1,0 & & 1,0 \\
\hline & 8 & $\begin{array}{l}\text { Proteção do tráfego local (velocidade e } \\
\text { proximidade/ separação fisica) }\end{array}$ & 0 & & 0 \\
\hline RESULTADOS & & Média individual e geral & 1,91 & & 1,91 \\
\hline
\end{tabular}

Figura 15: Tabela de Avaliação da Caminhabilidade da Rota 1 Brotas (Barbosa, 2016)

Não há rampas de acessibilidade e mesmo que houvesse uma pessoa em cadeira de rodas e/ou algum tipo de limitação de mobilidade, necessitaria de apoio para subir a escadaria para acessar a estação. $O$ único trecho de travessia é perigoso, pois é o acesso à via marginal da Av. Bonocô, onde o fluxo de veículos é grande, em apenas um sentido e não tem sinalização horizontal com faixas de pedestres. Não há nenhum tipo de proteção entre a calçada e a avenida e o tráfego é intenso durante todo o dia.

Na Rota 1 a afluência do tráfego sobre a calçada é regular. As larguras das calçadas precisam ser revistas, assim como às condições do piso (com desníveis, buracos, reparos e fissuras). A rota é apenas de passagem, e não é acessível. Um transeunte que possua alguma deficiência ou tenha mobilidade reduzida e faça uso de órtese, não tem condições de percorrê-la com autonomia.

Já a Rota 2 (seta roxa na figura 13) é dividida em lado direito e esquerdo. Para chegar à Estação de Brotas, são percorridos aproximadamente $130 \mathrm{~m}$. O início da rota começa na Rua Frederico Costa. Como mostra a figura 16, a Rota 2 é marcada pela qualidade do uso do solo e pela boa densidade de pessoas. Com um índice de caminhabilidade regular, sua média de caminhabilidade $(2,72)$ foi favorecida por estes dois critérios.

\begin{tabular}{|c|c|c|c|c|c|}
\hline \multicolumn{3}{|r|}{ CRITÉRIOS } & $\begin{array}{c}\text { NOTA } \\
\text { (0-5) } \\
\text { LD }\end{array}$ & $\begin{array}{c}\text { NOTA } \\
(0-5) \\
\text { LE }\end{array}$ & MÉDIA \\
\hline \multirow{2}{*}{ ATRATIVIDADE } & 1 & Densidade de Pessoas & 3,8 & 4,2 & 4,0 \\
\hline & 2 & Uso do Solo Lindeiro & 4,0 & 4,0 & 4,0 \\
\hline \multirow{6}{*}{ CONFORTO } & \multicolumn{5}{|c|}{ Fluência do tráfego sobre a calçada } \\
\hline & \multirow{2}{*}{3} & Densidade De Pessoas & 3,8 & 4,2 & 4,0 \\
\hline & & Largura da Calçada & 2,0 & 4,0 & 3,0 \\
\hline & 4 & $\begin{array}{l}\text { Condiçōes do piso*/ Existência } \\
\text { de Obstáculos/ Nivelamento do piso }\end{array}$ & 3,0 & 3,0 & 3,0 \\
\hline & 5 & Proteção intempéries & 2,0 & 2,0 & 2,0 \\
\hline & 6 & Mobiliário urbano** & 1,0 & 1,0 & 1,0 \\
\hline \multirow[b]{2}{*}{ SEGURANÇA } & 7 & Segurança de travessoa para o pedestre & 2,0 & 1,0 & 1,5 \\
\hline & 8 & $\begin{array}{l}\text { Proteção do tráfego local (velocidade e } \\
\text { proximidade/ separação fisica) }\end{array}$ & 2,0 & 2,0 & 2,0 \\
\hline RESULTADOS & & Média individual e geral & 2,62 & 2,82 & 2,72 \\
\hline
\end{tabular}

Figura 16: Tabela de Avaliação da Caminhabilidade da Rota 2 Brotas (Barbosa, 2016)

O uso do solo lindeiro misto da atual ocupação dos históricos casarões, com comércio, residência e serviços, contribui para uma boa dinâmica de ocupação, favorecendo a alta densidade de pessoas circulando na região ao longo do dia.

A largura da calçada é variável, com pontos entre $2 \mathrm{~m}$ e $3 \mathrm{~m}$ (dois e três metros), que inclui a divisão entre faixa de serviço e faixa livre. Há trechos danificados e com buracos. Em toda a rota há apenas uma rampa de acessibilidade, e também, um ponto com trilha tátil sem continuidade. 
Em nenhum local de travessia há semáforos (há apenas sinalização horizontal - faixa de pedestres) e o fluxo de veículos é intenso nos dois sentidos sem barreiras de proteção física para os pedestres.

Com uma média geral de 2,72 a Rota 2 tem uma caminhabilidade regular. A calçada é possível de ser percorrida de forma autônoma por um pedestre sem limitações físicas, que possa contornar os obstáculos existentes. Porém, portadores de qualquer tipo de necessidades especiais serão postos em risco em algum momento da rota. Foi comum observar pessoas em cadeira de rodas deslocando-se pelo leito carroçável.

A Rota 3 (seta verde na figura 13), assim como a anterior, possui lado direito e esquerdo. Para chegar à Estação de Brotas, são percorridos aproximadamente $210 \mathrm{~m}$ pelo trajeto do lado direito e aproximadamente $105 \mathrm{~m}$ pelo trajeto do lado esquerdo.

O início da Rota 3 é na Ladeira dos Galés. Como mostra a figura 17, a Rota 3 possui dois critérios ruins, a largura da calçada e o mobiliário urbano. Com um índice de caminhabilidade regular, sua média de caminhabilidade $(2,49)$ foi favorecida pelo uso do solo e pela alta densidade de pessoas.

\begin{tabular}{|c|c|c|c|c|c|}
\hline \multicolumn{3}{|r|}{ CRITÉRIOS } & $\begin{array}{c}\text { NOTA } \\
\text { (0-5) } \\
\text { LD }\end{array}$ & $\begin{array}{c}\text { NOTA } \\
\text { (0-5) } \\
\text { LE }\end{array}$ & MÉDIA \\
\hline \multirow{2}{*}{ ATRATIVIDADE } & 1 & Densidade de Pessoas & 4,4 & 4,0 & 4,2 \\
\hline & 2 & Uso do Solo Lindeiro & 3,0 & 3,0 & 3,0 \\
\hline \multirow{6}{*}{ CONFORTO } & \multicolumn{5}{|c|}{ Fluência do tráfego sobre a calçada } \\
\hline & \multirow{2}{*}{3} & Densidade De Pessoas & 4,4 & 4,0 & 4,2 \\
\hline & & Largura da Calçada & 2,0 & 1,0 & 1,5 \\
\hline & 4 & $\begin{array}{l}\text { Condiçōes do piso*/ Existência } \\
\text { de Obstáculos/ Nivelamento do piso }\end{array}$ & 3,0 & 2,0 & 2,5 \\
\hline & 5 & Proteção intempéries & 3,0 & 1,0 & 2,0 \\
\hline & 6 & Mobiliário urbano** & 1,0 & 1,0 & 1,0 \\
\hline \multirow[b]{2}{*}{ SEGURANÇA } & 7 & Segurança de travessoa para o pedestre & 2,0 & 2,0 & 2,0 \\
\hline & 8 & $\begin{array}{l}\text { Proteção do tráfego local (velocidade e } \\
\text { proximidade/ separação fisica) }\end{array}$ & 2,0 & 2,0 & 2,0 \\
\hline RESULTADOS & & Média individual e geral & 2,76 & 2,22 & 2,49 \\
\hline
\end{tabular}

Figura 17: Tabela de Avaliação da Caminhabilidade da Rota 3 Brotas

(Barbosa, 2016)

O mobiliário urbano se resume ao encontrado na região: postes de iluminação/energia, telefones públicos e lixeiras. Há no percurso um container de entulho/ lixo posicionado no local onde seria a faixa de acesso a uma edificação, estando fora do seu local correto de instalação que é no leito carroçável, próximo ao meio fio.

As calçadas são estreitas, com larguras entre 1,0m e 2,0m. Observamos na figura 18 que a condição do piso apresenta qualidade regular para caminhada, com desníveis, rebaixamento inadequado para acesso de veículos, buracos, obstáculos, poças d'água, piso impróprio, escorregadio e com propensão à queda. Há também pontos onde a inclinação transversal supera os $3 \%$ sugeridos por norma.
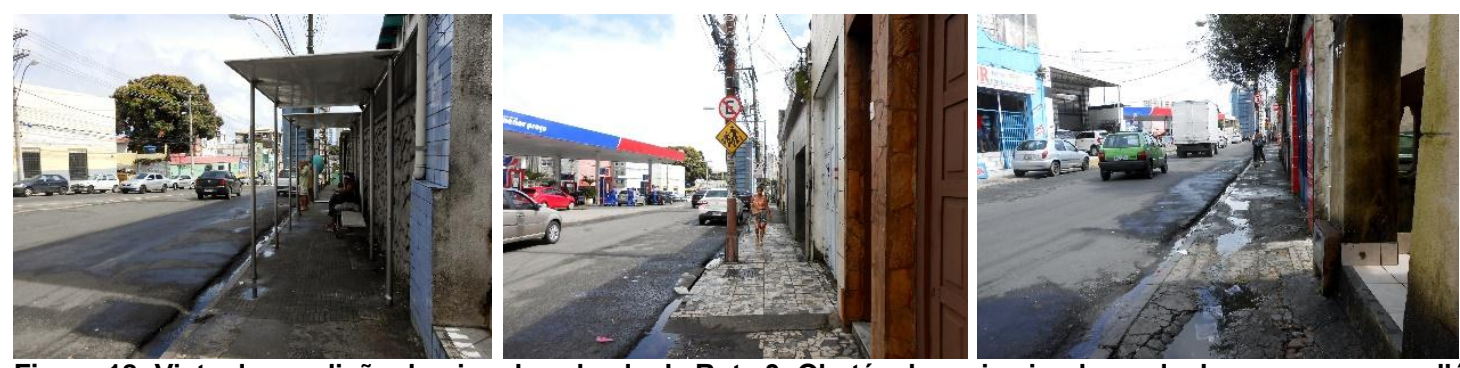

Figura 18: Vista da condição do piso da calçada da Rota 3: Obstáculos, piso inadequado, buracos e poças d'água. (Barbosa, 2015)

Vale ressaltar que o leito carroçável está no mesmo nível da calçada, fora dos padrões estabelecidos, que sugere que o mesmo esteja identificado por elementos separadores, ou por diferença de nível. Além da largura, as condições físicas das calçadas configuram um grande problema. As mesmas estão degradadas, desniveladas, com obstáculos e ausência de escoamento. Não há acessibilidade.

$\mathrm{Na}$ Rota 4, para chegar à Estação Brotas, são percorridos aproximadamente $226 \mathrm{~m}$ pela rota do lado direito e aproximadamente $205 \mathrm{~m}$ pela rota do lado esquerdo. O assentamento é composto por edificações antigas 
de um a dois pavimentos, geminadas, sem nenhum tipo de recuo e por edificações novas, com recuo lateral e frontal. É predominante o fechamento com gradis da maior parte dos imóveis.

Observamos na figura 19 que na Rota 4 (seta laranja na figura 13), os piores critérios avaliados são os referentes à qualidade física da calçada (Largura e Condições do Piso), em conjunto com proteção intempéries, todos classificados como ruins. Essa foi mais uma rota com a média geral $(2,28)$ favorecida pela densidade de pessoas e o uso do solo.

\begin{tabular}{|c|c|c|c|c|c|}
\hline \multicolumn{3}{|r|}{ CRITÉRIOS } & $\begin{array}{c}\text { NOTA } \\
(0-5) \\
\text { LD }\end{array}$ & $\begin{array}{c}\text { NOTA } \\
\begin{array}{c}(0-5) \\
\text { LE }\end{array}\end{array}$ & MÉDIA \\
\hline \multirow{2}{*}{ ATRATIVIDADE } & 1 & Densidade de Pessoas & 4,6 & 4,8 & 4,7 \\
\hline & 2 & Uso do Solo Lindeiro & 3,0 & 3,0 & 3,0 \\
\hline \multirow{6}{*}{ CONFORTO } & \multicolumn{5}{|c|}{ Fluência do tráfego sobre a calçada } \\
\hline & \multirow{2}{*}{3} & Densidade De Pessoas & 4,6 & 4,8 & 4,7 \\
\hline & & Largura da Calçada & 1,0 & 1,0 & 1,0 \\
\hline & 4 & $\begin{array}{l}\text { Condições do piso*/ Existência } \\
\text { de Obstáculos/ Nivelamento do piso }\end{array}$ & 2,0 & 1,0 & 1,5 \\
\hline & 5 & Proteção intempéries & 1,0 & 0 & 0,5 \\
\hline & 6 & Mobiliário urbano** & 1,0 & 1,0 & 1,0 \\
\hline \multirow[b]{2}{*}{ SEGURANÇA } & 7 & Segurança de travessoa para o pedestre & 2,0 & - & 2,0 \\
\hline & 8 & $\begin{array}{l}\text { Proteção do tráfego local (velocidade e } \\
\text { proximidade/ separação fisica) }\end{array}$ & 3,0 & 1,0 & 2,5 \\
\hline RESULTADOS & & Média individual e geral & 2,47 & 2,08 & 2,28 \\
\hline
\end{tabular}

Figura 19: Tabela de Avaliação da Caminhabilidade da Rota 4 Brotas (Barbosa, 2016)

A condição das calçadas é ruim. Há pontos com inclinação transversal acima de $3 \%$, tampas de caixas de inspeção na área de circulação não niveladas com o piso adjacente, entulhos, obstáculos (carros estacionados sob a calçada), buracos, pontos de estreitamento da faixa livre e áreas sem pavimentação (ver figura 20 abaixo).
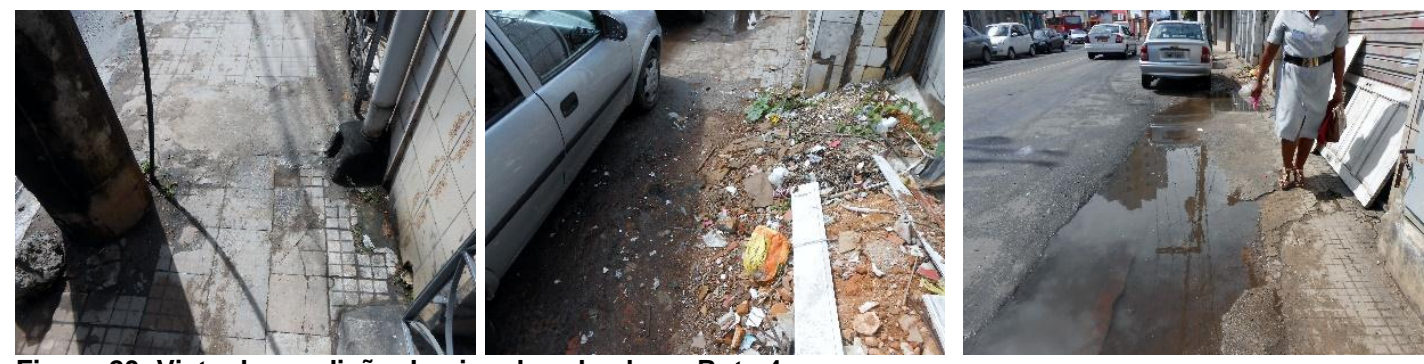

Figura 20: Vista da condição do piso da calçada na Rota 4 (Barbosa, 2015)

As calçadas são estreitas, com largura entre 1,20m a 1,50m e sem rampas de acessibilidade. Quase não há mobiliário urbano, apenas postes de iluminação e algumas lixeiras. O quesito Proteção Intempéries é bastante ruim, com proteção insuficiente, pois grande número das edificações é fechado com gradis e sem marquises. Não nenhuma árvore no percurso.

Nesta rota existem balizadores e estacionamento de veículos ao longo do meio fio. Speck (2016) acredita que estacionamentos ao longo do meio fio, proporcionam uma sensação de segurança a quem se desloca na calçada, por servir de barreira de proteção contra o tráfego de veículos.

Na Rota 4, uma pessoa sem nenhum tipo de deficiência consegue concluir o trajeto, mesmo com as dificuldades e desconforto. Porém, uma pessoa portadora de algum tipo de deficiência, só tem como seguir para a estação pelo leito carroçável e não pela calçada.

A média geral da caminhabilidade obtida no entorno da Estação Brotas foi regular. Das quatro avaliações, três foram avaliadas como regular e uma como ruim. O pedestre enfrenta dificuldade ao longo do percurso desde esforço físico à ausência de continuidade, bem como é exposto à riscos (pavimentação escorregadia, buracos, exposição ao fluxo de veículos, etc.). 


\subsection{Estação Bonocô}

Próxima a Estação Brotas e ao bairro do Matatu de Brotas, a Estação Bonocô está localizada no canteiro central da Avenida Mário Leal Ferreira (Av. Bonocô). A estação elevada atende diretamente aos bairros de Brotas, Cosme de Farias e Luiz Anselmo.

O bairro de Brotas com quase 64.000 habitantes, possui uma concentração residencial e um comércio intenso. De acordo com Santos (2010) é caracterizado também pelas diferenças sociais, com a parte rica no Horto Florestal e a parte mais pobre nas ocupações espontâneas da Polêmica e do Alto do Saldanha.

Já o bairro de Cosme de Farias, segundo Santos et al. (2010: 158), é da "década de sessenta, com a ocupação das encostas e baixadas que margeavam a sua rua principal". Da mesma forma tem o bairro Luiz Anselmo, com uma ocupação espontânea e nas encostas, com edificações residenciais.

Assim, o entorno desta estação é de bairros densos, onde se destaca a ocupação nas encostas (figura 21). A Avenida Bonocô evidencia tanto a conformação geográfica da cidade, quanto a segregação socioeconômica, refletida nos modos de deslocamento e de transporte.

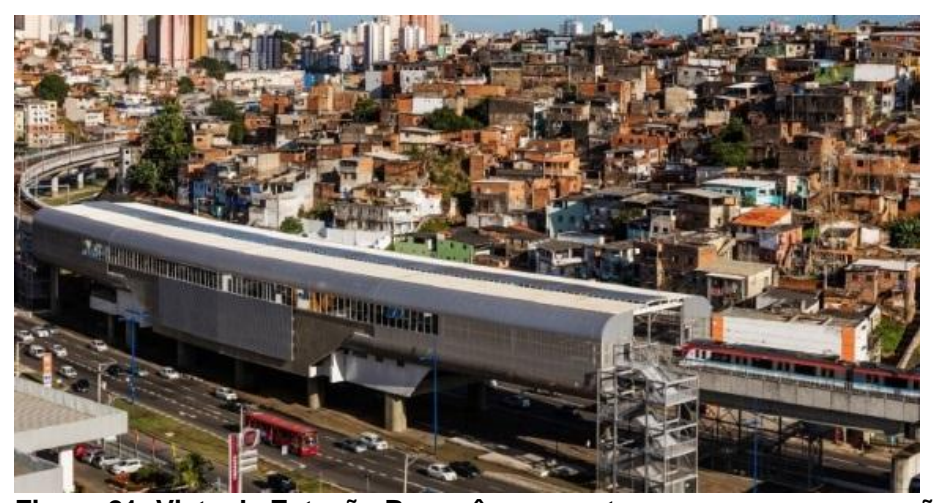

Figura 21: Vista da Estação Bonocô e seu entorno, com uma ocupação densa e informal na encosta.

(Nelson Kon, 2015)

O acesso à estação é feito por um conjunto de passarelas, posicionadas nas calçadas que margeiam a avenida e no canteiro central. Há acesso direto entre a estação e o canteiro central, por quatro escadarias (duas em cada ponta da estação), mas as mesmas são tratadas como de emergência, não sendo utilizadas, ficam trancadas diariamente.

Internamente a Estação Bonocô conta com duas plataformas laterais, sendo acessadas por escadas, escadas rolantes e elevadores. Sua área é de $6.140 \mathrm{~m}^{2}$ e inclui quatro sanitários e um bicicletário, localizado no canteiro central, abaixo da estrutura metroviária.

Para a avaliação da caminhabilidade, foram identificados os pontos de ônibus mais próximos e demarcadas as rotas (figura 22). In loco foi percebido o deslocamento de pedestres pelo canteiro central, desta forma, ainda que a avaliação seja simples e incompleta, os dois trajetos pelo canteiro central (abaixo da estrutura do metrô), são as Rotas 5 e 6. 


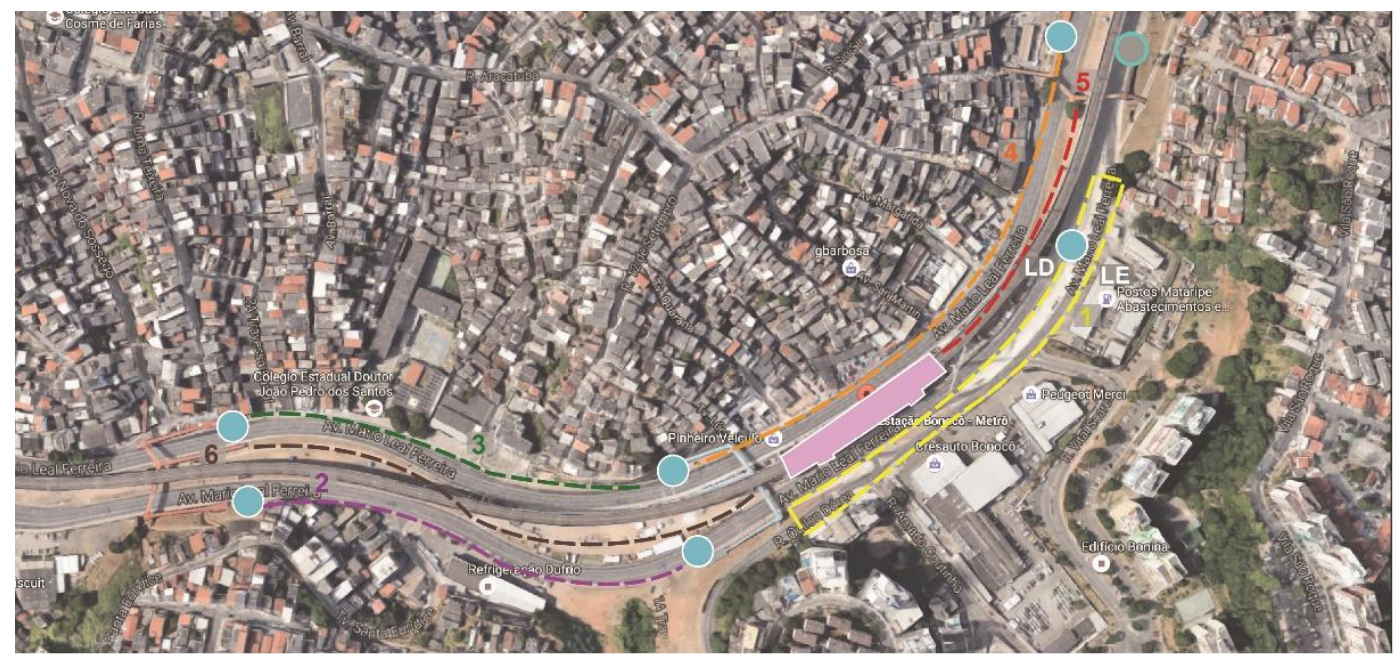

LEGENDA:

Imagens $\$ 2016$ Google,Dados do mapa $\$ 2016$ Google $50 \mathrm{~m}$

ESTAÇÃO BONOCO̊ PONTO DE ÔNIBUS

PONTO DE ÓNIBUS 三三三: SENTIDO DAS ROTAS

Figura 22: Identificação das Rotas do entorno da Estação Bonocô

Elaborado pela autora com base em imagem do Google Maps

A Rota 1 começa na ilha dos pontos de ônibus localizada na Av. Bonocô. O percurso da rota só foi definido na visita à campo, no qual foi observado duas rotas frequentes utilizadas pelos transeuntes: a Rota 1 lado direito com o trajeto entre as ilhas (canteiros) passando pelos acessos dos veículos da Av. Bonocô para a via marginal; e a outra Rota 1 lado esquerdo, pela calçada da via marginal.

A Rota 1 do lado direito, possui aproximadamente $423 \mathrm{~m}$ a serem percorridos até à estação já na Rota 1 esquerda, são aproximadamente $585 \mathrm{~m}$. Observamos na figura 23 que são três os critérios classificados como ruins: uso do solo, proteção intempéries e segurança na travessia. A densidade de pessoas, a largura da calçada e as condições do piso foram melhores avaliadas. A média da caminhabilidade foi regular $(2,37)$.

\begin{tabular}{|c|c|c|c|c|c|}
\hline \multicolumn{3}{|r|}{ CRITÉRIOS } & $\begin{array}{c}\text { NOTA } \\
(0-5) \\
\text { LD }\end{array}$ & $\begin{array}{c}\text { NOTA } \\
(0-5) \\
\text { LE }\end{array}$ & MÉDIA \\
\hline \multirow{2}{*}{ ATRATIVIDADE } & 1 & Densidade de Pessoas & 3,4 & 3,4 & 3,4 \\
\hline & 2 & Uso do Solo Lindeiro & 1,0 & 1,0 & 1,0 \\
\hline \multirow{6}{*}{ CONFORTO } & \multirow{3}{*}{3} & \multicolumn{4}{|c|}{ Fluência do tráfego sobre a calçada } \\
\hline & & Densidade De Pessoas & 3,4 & 3,4 & 3,4 \\
\hline & & Largura da Calçada & 5,0 & 2,0 & 3,5 \\
\hline & 4 & $\begin{array}{l}\text { Condiçōes do piso*/ Existência } \\
\text { de Obstáculos/ Nivelamento do piso }\end{array}$ & 4,0 & 2,0 & 3,0 \\
\hline & 5 & Proteção intempéries & 1,0 & 2,0 & 1,5 \\
\hline & 6 & Mobiliário urbano** & 2,0 & 2,0 & 2,0 \\
\hline \multirow[b]{2}{*}{ SEGURANÇA } & 7 & Segurança de travessoa para o pedestre & 1,0 & 2,0 & 1,5 \\
\hline & 8 & $\begin{array}{l}\text { Proteção do tráfego local (velocidade e } \\
\text { proximidade/ separação fisica) }\end{array}$ & 2,0 & 2,0 & 2,0 \\
\hline RESULTADOS & & Média individual e geral & 2,53 & 2,20 & 2,37 \\
\hline
\end{tabular}

Figura 23: Tabela de Avaliação da Caminhabilidade da Rota 1 Bonocô

(Barbosa, 2016)

A Proteção contra intempéries é pontual com a cobertura do posto de gasolina. Sobre o posto, ressaltamos que segundo a Lei de Calçada de Salvador (Lei no 8140, de 08 de novembro de 2011), o rebaixamento da guia da calçada, para o acesso dos veículos ao posto, não pode ser maior que $50 \%$ do total da testada do lote e não pode ultrapassar $7,0 \mathrm{~m}$ contínuos. No posto da rota o rebaixamento é feito ao longo de toda a extensão da testada e não existe sinalização para os pedestres referente à entrada e saída de veículos.

A Segurança de travessia é ruim, ainda que os veículos venham em um único sentido e reduzindo sua velocidade. A movimentação de veículos é intensa, com velocidade alta e sem barreiras. $O$ pedestre durante a rota deve estar atento à entrada e saída dos veículos das edificações lindeiras. 
Embora seja o percurso mais curto de deslocamento, a Rota 1 do lado direito, não deveria ser uma rota, visto que existe uma dupla interrupção do percurso do pedestre, para o acesso dos veículos que saem da via arterial para à via marginal, configurando trechos com risco de atropelamento (figura 24).
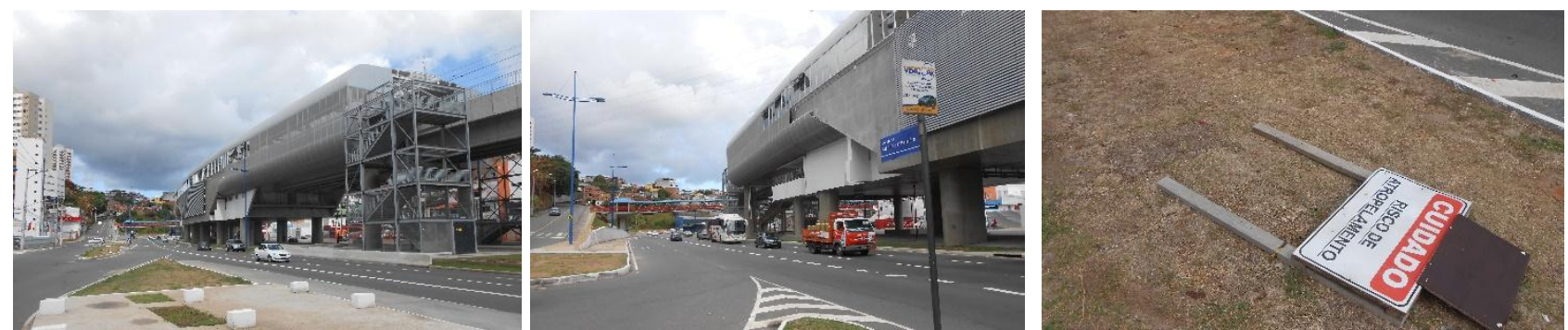

Figura 24: Vista dos pontos de travessia da Rota 1 lado direito

(Barbosa, 2016)

Na Rota 2 para chegar à passarela de acesso a Estação Bonocô são percorridos aproximadamente 475m. Esta rota é pouco utilizada e com um índice de caminhabilidade ruim $(1,53)$ é marcada pela falta de atratividade e acessibilidade (ver figura 25).

\begin{tabular}{|c|c|c|c|c|c|}
\hline \multicolumn{3}{|r|}{ CRITÉRIOS } & $\begin{array}{c}\text { NOTA } \\
(0-5) \\
\text { LD }\end{array}$ & $\begin{array}{c}\text { NOTA } \\
(0-5) \\
\text { LE }\end{array}$ & MÉDIA \\
\hline \multirow{2}{*}{ ATRATIVIDADE } & 1 & Densidade de Pessoas & 2,4 & & 2,4 \\
\hline & 2 & Uso do Solo Lindeiro & 1,0 & & 1,0 \\
\hline \multirow{6}{*}{ CONFORTO } & \multicolumn{5}{|c|}{ Fluência do tráfego sobre a calçada } \\
\hline & \multirow{2}{*}{3} & Densidade De Pessoas & 2,4 & & 2,4 \\
\hline & & Largura da Calçada & 2,0 & & 2,0 \\
\hline & 4 & $\begin{array}{l}\text { Condições do piso*/ Existência } \\
\text { de Obstáculos/ Nivelamento do piso }\end{array}$ & 2,0 & & 2,0 \\
\hline & 5 & Proteção intempéries & 1,0 & & 1,0 \\
\hline & 6 & Mobiliário urbano** & 1,0 & & 1,0 \\
\hline \multirow[b]{2}{*}{ SEGURANÇA } & 7 & Segurança de travessoa para o pedestre & 1,0 & & 1,0 \\
\hline & 8 & $\begin{array}{l}\text { Proteção do tráfego local (velocidade e } \\
\text { proximidade/ separação fisica) }\end{array}$ & 1,0 & & 1,0 \\
\hline RESULTADOS & & Média individual e geral & 1,53 & & 1,53 \\
\hline
\end{tabular}

Figura 25: Tabela de Avaliação da Caminhabilidade da Rota 2 Bonocô (Barbosa, 2016)

O uso do solo é pouco diversificado, com algumas edificações abandonadas. Há pouca interface entre a calçada e os prédios existentes. Ao longo do percurso a densidade é baixa, porem no ponto de ônibus, é alta.

A Proteção contra Intempéries é insuficiente, as edificações não possuem marquises e são cercadas por gradis. A segurança, com Proteção do Tráfego e Segurança na travessia, é ruim. O fluxo de veículos na avenida é constante, em alta velocidade, sem barreira de proteção e a calçada estreita aumenta a sensação de insegurança (ver figura 26). No único ponto de travessia o pedestre fica exposto.

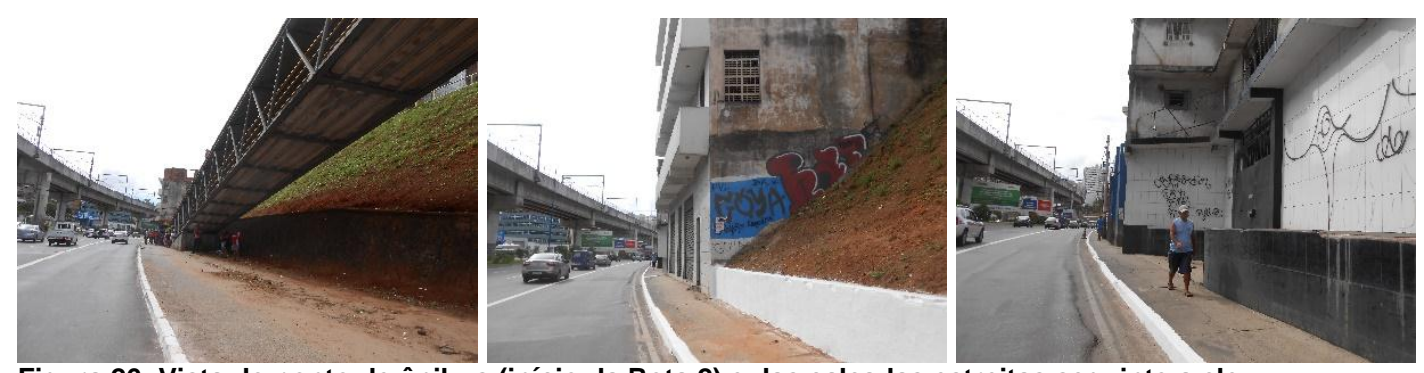

Figura 26: Vista do ponto de ônibus (início da Rota 2) e das calçadas estreitas seguinte a ele.

(Barbosa, 2016)

A Rota 3 é paralela a Rota 2. Para chegar à estação são percorridos aproximadamente 448m. Assim como a anterior, é pouco utilizada por quem quer usar o metrô, sendo trocada pela Rota 6 . A densidade, no entanto, é alta. 
Na figura 27 vemos que a Rota 3 tem um índice de caminhabilidade regular $(2,38)$. O uso do solo é favorecido pelo fato do comércio existente, há residências, mercados, lojas lanchonete, e equipamentos (um colégio estadual) e igrejas.

\begin{tabular}{|c|c|c|c|c|c|}
\hline \multicolumn{3}{|r|}{ CRITÉRIOS } & \multirow{2}{*}{$\begin{array}{c}\text { NOTA } \\
(0-5) \\
\text { LD }\end{array}$} & \multirow{2}{*}{$\begin{array}{c}\begin{array}{c}\text { NOTA } \\
(0-5) \\
\text { LE }\end{array} \\
3,2\end{array}$} & \multirow{2}{*}{$\begin{array}{c}\text { MÉDIA } \\
3,2\end{array}$} \\
\hline \multirow{2}{*}{ ATRATIVIDADE } & 1 & Densidade de Pessoas & & & \\
\hline & 2 & Uso do Solo Lindeiro & & 3,0 & 3,0 \\
\hline \multirow{6}{*}{ CONFORTO } & \multicolumn{5}{|c|}{ Fluência do tráfego sobre a calçada } \\
\hline & \multirow{2}{*}{3} & Densidade De Pessoas & & 3,2 & 3,2 \\
\hline & & Largura da Calçada & & 2,0 & 2,0 \\
\hline & 4 & $\begin{array}{l}\text { Condições do piso*/ Existência } \\
\text { de Obstáculos/ Nivelamento do piso }\end{array}$ & & 2,0 & 2,0 \\
\hline & 5 & Proteção intempéries & & 2,0 & 2,0 \\
\hline & 6 & Mobiliário urbano** & & 2,0 & 2,0 \\
\hline \multirow[b]{2}{*}{ SEGURANÇA } & 7 & Segurança de travessoa para o pedestre & & 2,0 & 2.0 \\
\hline & 8 & $\begin{array}{l}\text { Proteção do tráfego local (velocidade e } \\
\text { proximidade/ separação física) }\end{array}$ & & 2,0 & 2,0 \\
\hline RESULTADOS & & Média individual e geral & & 2,38 & 2,38 \\
\hline
\end{tabular}

Figura 27: Tabela de Avaliação da Caminhabilidade da Rota 3 Bonocô

(Barbosa, 2016)

Não há rampas de acessibilidade e a pavimentação possui condições precárias com buracos, sem pavimentação e áreas onde o meio fio já quase não existe. Não há nesta rota nenhuma preocupação quanto à continuidade e a acessibilidade para os pedestres.

São feitos desníveis nas calçadas e não há a preocupação em relação à execução de rampas para vencêlos. Informalmente, em conversa com transeuntes, foi descoberto que são frequentes assaltos no ponto de ônibus e na passarela que dá acesso ao canteiro central.

Da Rota 4 para a Estação Bonocô são percorridos aproximadamente $574 \mathrm{~m}$. Com uma média regular $(2,33)$, observamos na figura 28 que os piores índices são referentes à segurança do pedestre (Na travessia e proteção contra o tráfego).

\begin{tabular}{|c|c|c|c|c|c|}
\hline \multicolumn{3}{|r|}{ CRITÉRIOS } & $\begin{array}{c}\text { NOTA } \\
(0-5) \\
\text { LD }\end{array}$ & $\begin{array}{c}\text { NOTA } \\
(0-5) \\
\text { LE }\end{array}$ & MÉDIA \\
\hline \multirow{2}{*}{ ATRATIVIDADE } & 1 & Densidade de Pessoas & & 4,0 & 4,0 \\
\hline & 2 & Uso do Solo Lindeiro & & 2,0 & 2,0 \\
\hline \multirow{6}{*}{ CONFORTO } & \multicolumn{5}{|c|}{ Fluência do tráfego sobre a calçada } \\
\hline & \multirow{2}{*}{3} & Densidade De Pessoas & & 4,0 & 4,0 \\
\hline & & Largura da Calçada & & 2,0 & 2,0 \\
\hline & 4 & $\begin{array}{l}\text { Condições do piso*/ Existência } \\
\text { de Obstáculos/ Nivelamento do piso }\end{array}$ & & 2,0 & 2,0 \\
\hline & 5 & Proteção intempéries & & 3,0 & 3,0 \\
\hline & 6 & Mobiliário urbano** & & 2,0 & 2,0 \\
\hline \multirow[b]{2}{*}{ SEGURANÇA } & 7 & Segurança de travessoa para o pedestre & & 1,0 & 1,0 \\
\hline & 8 & $\begin{array}{l}\text { Proteção do tráfego local (velocidade e } \\
\text { proximidade/ separação fisica) }\end{array}$ & & 1,0 & 1,0 \\
\hline RESULTADOS & & Média individual e geral & & 2,33 & 2,33 \\
\hline
\end{tabular}

Figura 28: Tabela de Avaliação da Caminhabilidade da Rota 4 Bonocô (Barbosa, 2016)

O Uso do Solo é denso, mas pouco diversificado, composto por uma primeira faixa de comércio com segmento automotivo (peças de carros, revendedoras de veículos, posto de gasolina - de pouco interesse ao pedestre), mas, subindo a encosta, diversas edificações residenciais.

O assentamento é composto tanto por edificações de um a cinco pavimentos, geminadas, sem recuos. É predominante o padrão de autoconstrução. A densidade de pedestre é alta devido ao deslocamento vindo da encosta, pelas escadarias, para a avenida. 
Boa parte das escadarias apresentam problemas referente a ausência de manutenção e adequação à NBR9050, como: ausência total ou parcial de corrimãos, espelhos com alturas diversas, sem patamar e com iluminação precária.

As calçadas que margeiam a avenida não possuem nenhum tipo de proteção contra o tráfego local, em determinados pontos, por serem estreitas ou estarem com algum obstáculo, condicionam o pedestre a se expor andando pela pista de rolamento. Além disso, foi comum encontrar veículos estacionados em cima da calçada.

Como mostra a imagem 29, na Rota 4 é evidente que a prioridade no espaço urbano é dos veículos e não dos pedestres. As calçadas, que deveriam permanecer intactas, são modificadas para facilitar o acesso de veículos aos estacionamentos das lojas (além de serem ocupadas pelos carros, sem restrição).
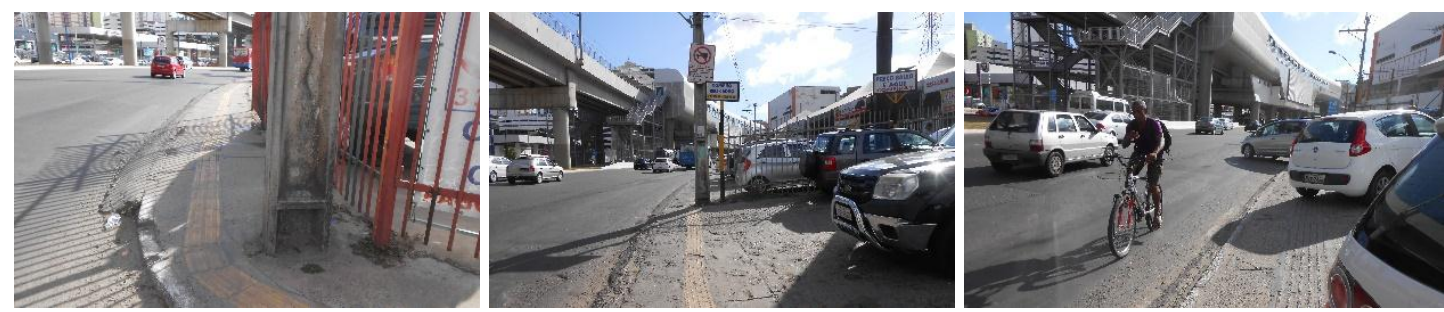

Figura 29: Vista da calçada ao longo da Rota 4. A prioridade do espaço urbano é destinada aos veículos.

(Barbosa, 2016)

As rotas táteis existentes não possuem continuidade, são instaladas em calçadas danificadas e com inclinações inadequadas Vemos na Rota 4 um reflexo do que acontece na cidade, o acesso ao transporte público é dificultado pela necessidade do deslocamento vertical.

A Rota 5 começa com a circulação vertical por rampa, vinda de ambos os lados da Av. Bonocô. É necessário atravessar a passarela até chegar a escada que faz a conexão do canteiro central. Para à estação são percorridos aproximadamente $579 \mathrm{~m}$.

A média de caminhabilidade boa $(3,4)$ é por conta de três critérios especificamente: Condições do piso, proteção intempéries e proteção contra ao tráfego de veículos. Vale salientar que o uso do solo foi desconsiderado nesta rota, já que ela é margeada por pistas.

\begin{tabular}{|c|c|c|c|c|c|}
\hline \multicolumn{3}{|r|}{ CRITÉRIOS } & $\begin{array}{l}\text { NOTA } \\
\text { (0.5) } \\
\text { LD }\end{array}$ & $\begin{array}{l}\text { NOTA } \\
\text { (0-5) } \\
\text { LE }\end{array}$ & MÉDIA \\
\hline \multirow{2}{*}{ ATRATIVIDADE } & 1 & Densidade de Pessoas & 3,4 & & 3,4 \\
\hline & 2 & Uso do Solo Lindeiro & - & & - \\
\hline \multirow{6}{*}{ CONFORTO } & \multicolumn{5}{|c|}{ Fluência do tráfego sobre a calçada } \\
\hline & \multirow{2}{*}{3} & Densidade De Pessoas & 3,4 & & 3,4 \\
\hline & & Largura da Calçada & 3,0 & & 3,0 \\
\hline & 4 & $\begin{array}{l}\text { Condições do piso*/ Existência } \\
\text { de Obstáculos/ Nivelamento do piso }\end{array}$ & 4,0 & & 4,0 \\
\hline & 5 & Proteção intempéries & 4,0 & & 4,0 \\
\hline & 6 & Mobiliário urbano** & 2,0 & & 2,0 \\
\hline \multirow[b]{2}{*}{ SEGURANÇA } & 7 & Segurança de travessoa para o pedestre & - & & - \\
\hline & 8 & $\begin{array}{l}\text { Proteção do tráfego local (velocidade e } \\
\text { proximidade/ separação física) }\end{array}$ & 4,0 & & 4,0 \\
\hline RESULTADOS & & Média individual e geral & 3,4 & & 3,4 \\
\hline
\end{tabular}

Figura 23: Tabela de Avaliação da Caminhabilidade da Rota 5 Bonocô (Barbosa, 2016)

A densidade de pedestre é alta, alimentada pelos fluxos de entrada e saída do metrô e de pessoas praticando atividades físicas (ciclismo, caminhada ou corrida). O item Proteção Intempéries é favorecido pela estrutura metroviária, que configura uma proteção contínua.

Quanto ao quesito segurança, foi avaliado apenas a Proteção do Tráfego. O tráfego de bicicleta não é grande, e o deslocamento é feito em uma pista separada da do pedestre. Com exceção do início da rota, o deslocamento segue de forma contínua (ser exigir nenhum tipo de cruzamento) até a passarela do metrô. 
Nessa rota de passagem (para quem não está fazendo atividade física), o deslocamento é mais rápido pois o movimento é linear, sem desníveis ou interrupções, além de ser, em boa parte do tempo, feito na sombra.

A Rota 6 começa com um deslocamento vertical, seguido de um deslocamento por passarela, até acessar a rampa que faz a conexão com o canteiro central. Para chegar à estação Bonocô são percorridos aproximadamente $535 \mathrm{~m}$.

Assim como na Rota 5, a média de caminhabilidade é boa $(3,63)$ é por conta de três critérios específicos: Condições do piso, proteção intempéries e proteção contra ao tráfego de veículos. A densidade de pessoas nessa rota, porém, é maior.

\begin{tabular}{|c|c|c|c|c|c|}
\hline \multicolumn{3}{|r|}{ CRITÉRIOS } & $\begin{array}{c}\text { NOTA } \\
(0-5)\end{array}$ & $\begin{array}{c}\text { NOTA } \\
(0-5) \\
(E\end{array}$ & MÉDIA \\
\hline \multirow{2}{*}{ ATRATIVIDADE } & 1 & Densidade de Pessoas & 3,7 & & 3,7 \\
\hline & 2 & Uso do Solo Lindeiro & - & & - \\
\hline \multirow{6}{*}{ CONFORTO } & & \multicolumn{4}{|c|}{ Fluência do tráfego sobre a calçada } \\
\hline & \multirow{2}{*}{3} & Densidade De Pessoas & 3,7 & & 3,7 \\
\hline & & Largura da Calçada & 3,0 & & 3,0 \\
\hline & 4 & $\begin{array}{l}\text { Condições do piso*/ Existência } \\
\text { de Obstáculos/ Nivelamento do piso }\end{array}$ & 4,0 & & 4,0 \\
\hline & 5 & Proteção intempéries & 4,0 & & 4,0 \\
\hline & 6 & Mobiliário urbano** & 3,0 & & 3,0 \\
\hline \multirow[b]{2}{*}{ SEGURANÇA } & 7 & Segurança de travessoa para o pedestre & - & & - \\
\hline & 8 & $\begin{array}{l}\text { Proteção do tráfego local (velocidade e } \\
\text { proximidade/ separação física) }\end{array}$ & 4,0 & & 4,0 \\
\hline RESULTADOS & & Média individual e geral & 3,63 & & 3,63 \\
\hline
\end{tabular}

Figura 24: Tabela de Avaliação da Caminhabilidade da Rota 6 Bonocô (Barbosa, 2016)

Ao longo do trajeto encontramos além da ciclovia e da pista de caminhada, uma área de lazer que inclui conjuntos de mesas e bancos fixos, conjunto de brinquedos infantil, equipamentos de ginástica, quiosques, bancos (sem encosto), paraciclos e, já próximo à estação, uma quadra e um bicicletário.

Com pavimentação asfáltica e em concreto, o critério de condições do piso da calçada. Tanto a ciclovia, quanto a pista de caminhada estão bem conservadas não possuindo nenhum tipo de desnível ou obstáculos.

A acessibilidade é ruim. Até chegar ao canteiro central, uma pessoa em uma cadeira de rodas precisará de muita ajuda para fazer o deslocamento vertical. A circulação só se dá de forma autônoma, no canteiro central.

$\mathrm{Na}$ avaliação da caminhabilidade da Estação Bonocô, destacamos que as duas rotas com as médias boas, são as que exigem maior esforço físico dos usuários do metrô, devido à necessidade de se fazer mais deslocamentos verticais. Essas médias foram influenciadas pela densidade alta e pelas boas condições da calçada.

\section{CONSIDERAÇÕES FINAIS}

Diante de tudo que foi exposto, é necessário salientar que valorizar o transporte coletivo e implantar sistemas integrados são, na prática, ações de grande incentivo aos modais não motorizados, compondo inclusive, a quinta ação estratégica do PlanMob (2015) para solucionar os problemas da mobilidade urbana nas cidades brasileiras.

É o transporte público que conecta a cidade, um maior número de pessoas com os centros e as partes mais distantes. Da mesma forma, estimular o uso do solo misto, com espaços bem interligados e em vizinhanças densas, é uma ferramenta eficiente para o desenvolvimento de um bom espaço urbano.

Assim, dentro das premissas de Jacobs (2001), Gehl (2013) Lo (2009), Speck (2016), é necessário que existam no espaço urbano, para que ele seja bom, três condições essenciais: Segurança, Atratividade e Conforto. 
Todas essas questões visam encorajar o deslocamento a pé como a principal forma de mobilidade na cidade, pois o mesmo é o princípio necessário da grande maioria das viagens por transporte coletivo. $O$ modo a pé é atingido diretamente pelas condições ambientais e físicas do desenho da cidade.

Buscar soluções mecânicas que facilitem o transporte vertical é importante e necessário. A topografia de Salvador exige a implantação destes tipos de modais de transporte. Embora em dado momento, com a expansão da cidade e a adoção de um modelo rodoviarista, Salvador tenha optado por "abrir mão" e não investir em uma expansão do número desses equipamentos urbanos, a capital baiana possui um histórico exitoso com os exemplos dos planos inclinados (Gonçalves, Pilar e Calçada-Lapa) e dos elevadores (Lacerda e do Taboão).

Tais modais de deslocamento, somados ao sistema de transporte público coletivo por ônibus, e atualmente, somado também ao metrô, facilitaria o acesso das cumeadas aos vales, sendo as avenidas de vale nossos principais corredores de transporte.

Os resultados da avaliação da caminhabilidade no entrono das estações Brotas e Bonocô, mostram que a média da caminhabilidade avaliada nas rotas possui nível regular, na qual a qualidade dos percursos não está adequada para o deslocamento a pé.

Das dez rotas avaliadas (quatro da Estação Brotas e seis da Estação Bonocô) duas foram classificadas como ruins (notas entre 0 e 2), seis foram classificadas como regulares (notas entre 2 e 3 ) e duas foram classificadas como boas (notas entre 3 e 5). Desta forma, o deslocamento entre modais (ônibus/metrô) não está em pauta no planejamento da cidade.

A microacessibilidade no percurso do usuário ao transporte público é ruim e exige esforço físico. Destacamos nas avaliações das duas estações, que as notas boas foram influenciadas principalmente pela densidade (alta) e pelo uso do solo. As condições físicas (piso, proteção contra intempéries, proteção contra o tráfego, ausência de obstáculos, etc.) e escassez de mobiliário urbano, influenciaram para notas regulares e ruins.

Pontos sem pavimentação, com buracos, poças d'água, obstáculos, desníveis, configuram fatores que dificultam o deslocamento do pedestre e mais ainda de uma pessoa com mobilidade reduzida ou em cadeira de rodas. A acessibilidade não existe.

A hierarquia no entorno de ambas as estações prioriza os percursos dos veículos automotores. A integração dos modais de transporte deixa a desejar. Os espaços destinados aos pedestres são as sobras do espaço dos veículos. Para os pedestres estão destinados os percursos mais difíceis e os menos diretos.

Os resultados da avaliação nos ajudam a identificar os pontos que precisam receber maior atenção e intervenções imediatas. Desta forma, destacamos também, de acordo com tudo que foi apresentado, que a proposta metodológica (tabela de avaliação) necessita de ajustes quanto ao papel dos critérios na pontuação final, considerando incluir à metodologia, fatores de ponderação para que os resultados finais sejam mais precisos.

É importante também pensar um critério que avalie melhor as questões referentes ao tecido urbano, bem como no desgaste físico do usuário. Diante disto, a tabela de avaliação se apresenta adequada para ser utilizada apenas em avaliações de caminhabilidade preliminares, servindo de base para subsidiar pesquisas mais detalhadas.

Enquanto não se pensar cidades humanas, para pessoas como diz Gehl (2013), prezando pela qualidade dos deslocamentos a pé e fornecendo as condições físicas mínimas necessárias para a realização de tal, não haverá mobilidade sustentável e ainda será mantida a predominância do uso de veículos particulares.

A qualidade física das calçadas e a falta de segurança são dois elementos que desestimulam a circulação na cidade. Em termos práticos, executar e manter uma calçada não é caro. Em Salvador, especificamente, o preço unitário por metro quadrado, é abaixo dos $R \$ 100,00$.

Assim, fiscalizar e exigir que, principalmente as novas edificações sigam as diretrizes da NBR 9050, que garantem o mínimo necessário para um deslocamento autônomo, não é impossível de ser feito pela esfera municipal. Garantir uma boa caminhabilidade é proporcionar uma mobilidade urbana justa e equitativa. 
Isto posto, as cidades só estarão mais próximas de uma mudança real na forma de se fazer planejamento urbano, se os gestores públicos e profissionais envolvidos - Arquitetos e Urbanistas, Engenheiros de Transportes, Técnicos do Governo, etc. - levarem em consideração aspectos que priorizem os modos não motorizados, evitando o direcionamento de verbas para projetos e obras desnecessários e desconectados como a realidade urbana. Aí sim, o planejamento será feito na escala humana, para pessoas.

\section{BIBLIOGRAFIA}

\section{Obra Completa:}

BARBOSA, V. V. O. (2016) Avaliação da caminhabilidade no entorno de estações da Linha 1 do metrô de Salvador. Dissertação (mestrado) - Universidade Federal da Bahia, Faculdade de Arquitetura, Salvador. 141.

BRITO, F. L. (2008) Direito à calçada: o espaço e o pedestre na cidade de Salvador- BA. Dissertação de Mestrado - Universidade Católica do Salvador. Salvador. 176.

CARERI, F. (2013) Walkscapes. O caminhar como prática estética. Barcelona: Gustavo Gili.

GEHL, J. (2013) Cidades para Pessoas. São Paulo: Perspectiva.

ITDP, Instituto de Políticas de Transporte \& Desenvolvimento. (2013) Padrão de Qualidade TOD v2.0. Rio de Janeiro. Gráfica: Lógus Gráfica.

JACOBS, J. (2001) Morte e Vida nas Grandes Cidades. São Paulo: Martins Fontes.

LATORRACA, G. (2000) João Filgueiras Lima, Lelé. Série Arquitetos Brasileiros. São Paulo: Blau, Instituto Lina Bo e P.M. Bardi.

PAIXÃO, R. C. da. (2011) Análise espacial das condições de deslocamento do pedestre na integração com o transporte público. Dissertação (mestrado) - Universidade Federal da Bahia, Escola Politécnica. Salvador. 208.

LERNER, J. (2005) Acupuntura Urbana. Rio de Janeiro: Record.

SANTOS, E. et al. (2010) O Caminho das Águas em Salvador: Bacias Hidrográficas, Bairros e Fontes. Salvador: CIAGS/UFBA; SEMA.

SPECK, J. (2016) Cidade Caminhável. São Paulo: Perspectiva.

VASCONCELLOS, E. A. de (2012) Mobilidade urbana e cidadania. São Paulo: Senac.

\section{Capítulo de Livro:}

DELGADO, J. P. M. (2014). Organização Social do Território e Mobilidade Urbana. In: Carvalho, I. M.M e Pereira, G. C. (Org.). Metrópoles: Território, Coesão Social e Governança Democrática / Salvador: Transformações na Ordem Urbana (199-234). Rio de Janeiro: Letra Capital.

\section{Revistas:}

ANTP. Transporte e Mobilidade Sustentável. (2005) Tese da Comissão de Meio Ambiente da ANTP. Revista dos Transportes Públicos - ANTP, 107/108, 81-92.

GHIDINI, R. (2011) A caminhabilidade: medida urbana sustentável. Revista dos Transportes Públicos ANTP, 33, 21-33.

LO, H. R. (2009) Walkability: what is it? Journal of Urbanism: International Research on Placemaking and Urban Sustainability, 2:2, 145-166. 


\section{Leis e Decretos:}

ASSOCIAÇÃO BRASILEIRA DE NORMAS TÉCNICAS - ABNT. NBR9050 (2015) Acessibilidade a edificações, mobiliário, espaços e equipamentos urbanos. ABNT.

DENATRAN - DEPARTAMENTO NACIONAL DE TRÂNSITO (2008) Código de Trânsito Brasileiro.

MINISTÉRIO DAS CIDADES. (2015) Caderno de referência para elaboração de Plano de Mobilidade Urbana: PlanMob. Brasília: Ministério das Cidades.

PREFEITURA MUNICIPAL DE SALVADOR. Lei № 7.400/2008. Dispõe sobre o Plano Diretor de Desenvolvimento Urbano do Município do Salvador - PDDU 2007 e dá outras providências. Salvador: PMS.

PREFEITURA MUNICIPAL DE SALVADOR. (1984) Lei de Ordenamento de Uso e Ocupação do Solo LOUOS, Salvador.

\section{Palestras, congressos, conferências e seminários:}

DELGADO, J. P. M., NASCIMENTO, K. A. S. e BAGGI, M. S. (2007) Avaliação da microacessibilidade e mobilidade do pedestre e das pessoas com necessidades especiais num terminal de transporte urbano, na cidade de Salvador, Bahia. XIV Congresso Latino-Americano de transporte público e urbano, Rio de Janeiro.

RODRIGUES, M. A. N., MATOS, C. H. (2013) Avaliação das Condições de Caminhabilidade nas Áreas Centrais de Salvador e Aracaju, Brasil. XV Congresso Iberoamericano de Urbanismo, Medellín. 